\title{
Effect of Various Wafer Surface Etching Processes on c-Si Solar Cell Characteristics
}

\author{
Jeong Eun Park ${ }^{1}$, Chang-Soon Han ${ }^{2}$, Won Seok Choi ${ }^{3}$ and Donggun Lim ${ }^{1,3, *}$ \\ 1 Department of Electronic Engineering, Korea National University of Transportation, Chungju 27909, Korea; \\ ac1331@ut.ac.kr \\ 2 Jeonnam Technopark, \#370, Green-ro, Jeollanam-do 58324, Korea; cshan@jntp.or.kr \\ 3 Department of IT Energy Convergence, Korea National University of Transportation, Chungju 27909, Korea; \\ giant29@ut.ac.kr \\ * Correspondence: dglim@ut.ac.kr
}

Citation: Park, J.E.; Han, C.-S.; Choi, W.S.; Lim, D. Effect of Various Wafer Surface Etching Processes on c-Si Solar Cell Characteristics. Energies 2021, 14, 4106. https://doi.org/ $10.3390 /$ en14144106

Academic Editor: Adalgisa Sinicropi

Received: 9 June 2021

Accepted: 5 July 2021

Published: 7 July 2021

Publisher's Note: MDPI stays neutral with regard to jurisdictional claims in published maps and institutional affiliations.

Copyright: () 2021 by the authors. Licensee MDPI, Basel, Switzerland. This article is an open access article distributed under the terms and conditions of the Creative Commons Attribution (CC BY) license (https:// creativecommons.org/licenses/by/ $4.0 /)$.

\begin{abstract}
In order to analyze the effects of various sizes of pyramid structure on solar cell characteristics, a pyramid structure was formed on the wafer through various etching processes. In this paper, etching was performed using one-step etching processes such as alkaline solution etching, reactive ion etching (RIE), and metal-assisted chemical etching (MACE), and two-step etching processes such as alkaline solution + MACE and alkaline solution + RIE. The micro-sized pyramid-structured wafers formed using the alkali solution showed higher reflectivity than nano-sized pyramid-structured wafers. Accordingly, it was expected that the characteristics of the cells fabricated with a nano-sized pyramid-structured wafer having low reflectivity would be higher than that of a micro-sized pyramidstructured wafer. However, it was confirmed that the quantum efficiency characteristics in the short wavelength region were higher in the micro-sized pyramid-structured wafers than in the nano-sized pyramid-structured wafers. To confirm the reason for this, surface characteristics were analyzed through the deposition of an emitter layer on a wafer formed in a pyramidal structure. As a result, in the case of the nano-sized pyramid-structured wafer, the sheet resistance characteristics were lower due to the increased depth of the emitter layer in comparison to the micro-sized pyramid-structured wafer. Accordingly, it was determined that the quantum efficiency was degraded as a result of the high recombination rate.
\end{abstract}

Keywords: crystalline Silicon (c-Si) solar cell; surface etching; metal-assisted chemical etching (MACE); reactive ion etching (RIE); reflectance

\section{Introduction}

Photovoltaic (PV) power generation is a very popular energy resource due to its ecofriendly and infinite nature. The current PV market has exceeded $627 \mathrm{GW}$ of accumulated installed capacity in 2019, and this is expected to increase further over time. As PV power generation presents the possibility of making leaps in technology when compared to national investment, it is time to secure various researches and technologies to extract maximum performance as a continuous energy supply source [1]. Currently, the main areas of interest in the photovoltaic field can be divided into two. The first area regards the development of high-efficiency solar cells to improve solar power generation efficiency. Various high-efficiency solar cell structures based on c-Si have been proposed. Examples of high-efficiency solar cell technology include: passivated emitter and rear cell (PERC) structured solar cells [2], manufactured by the insertion of anti-reflection film onto the back of a solar cell; LDSE structure solar cells [3] with a selective emitter applied; a bifacial solar cell with two-sided absorbing solar cells [4]; and tandem solar cells using perovskite solar cells $[5,6]$ as upper cells. The second area of interest revolves around lowering the costs of manufacturing PV cells. The materials that cost the most during the manufacture of solar cells are the wafer and silver paste. In order to manufacture a low-cost solar cell, it 
is essential to thin the wafer and reduce the amount of silver paste used. Si wafers have the highest share in price determination and research for the commercialization of c-Si solar cells containing a thinner structure is actively underway. As the thickness of the wafer decreases in order to reduce costs, the process method of wafers 180 to $200 \mu \mathrm{m}$ thick, which are commercially available, must be improved. For example, a wafer surface etching process using wet etching that consumes a large amount of $\mathrm{Si}$ is difficult to apply to a thin wafer. In order to compensate for this, various surface etching processes using reactive ion etching and metal catalytic chemical etching have been developed. In order to obtain a low-cost and high-efficiency solar cell, it is necessary to improve the process method while taking into account factors that reduce the efficiency of the solar cell. Factors that reduce the efficiency of a solar cell can be largely divided into recombination loss, resistance loss, and optical loss. Recombination loss is the process by which electrons and holes separated by light are recombined before being collected in the metal electrode, accordingly, it does not contribute to solar cell efficiency. In order to reduce recombination loss on the upper surface of a solar cell, a method is generally applied to reduce the number of dangling bonds on the surface by forming a passivation layer. In the case of rear surface recombination, this can be compensated for through the formation of a rear electric field with high concentration doping [7]. Loss due to resistance components can be divided into series resistance and parallel resistance, and various studies are being conducted to reduce each loss. The first factor that causes optical loss is shadow loss due to the front electrode. In a typical solar cell, an electrode is formed on the front surface of the light incident, and shadow loss occurs because the electrode cannot absorb light in the formed portion. In addition, optical loss is mainly caused by reflections occurring on the Si surface depending on the wavelength of the sunlight. In general, the surface of a Si wafer reflects more than $30 \%$ of light on average at a wavelength of $400 \sim 1000 \mathrm{~nm}[8,9]$. Solar cells can absorb light and create pairs of electrons and holes. However, when light is reflected from the surface of the solar cell, it eventually cannot be absorbed and thus does not generate electron and hole pairs. This decreases the short-circuit current of the solar cell and causes the output of the module to decrease [10]. In this paper we studied the effects on solar cell characteristics when minimizing optical loss across various efficiency loss factors. The etching process of the c-Si wafer increases the amount of absorbed light by increasing the passage length of light in the solar cell through a reduction of surface reflectance of incident light. Accordingly, the reduction of short-circuit current due to light reflection can be improved. The etching rate varies depending on the direction of the Si crystal, and a pyramid is formed on the wafer surface using the difference in the etching rate. The etching rate is fastest in the (100) direction surface of the wafer, and the etching rate in the (111) direction decreases about $1 / 100$ times, thereby obtaining a pyramid shape [11]. In the wafer on which the pyramid structure is formed, light is incident again to the substrate by the inclined surface, thus enabling increased absorption. The pyramid structure formed on the surface of c-Si plays an important role in the direction of light according to the formation angle. Figure 1 shows the path of light incident on the V-shaped surface according to the angle. At $\alpha=30^{\circ}$, only the lower part of the $\mathrm{V}$-shaped groove has a path through which light is reflected twice, and at $\alpha=45^{\circ}$ all incident light has a path through which it is reflected twice. At $\alpha=54^{\circ}$, only the lower part of the V-shaped groove has a path through which light is reflected three times, and at $\alpha=60^{\circ}$ all incident light has a path through which it is reflected three times. As the angle of the pyramid structure increases, the number of reflections increases, and the amount of light generated electrons increases. 


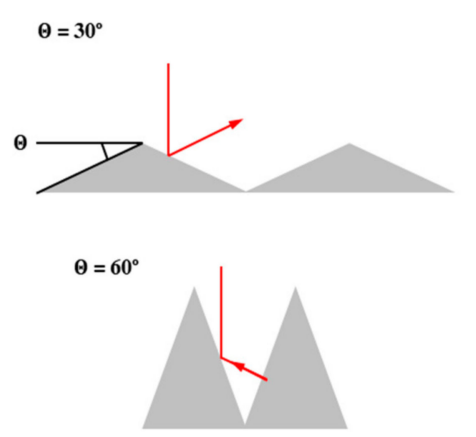

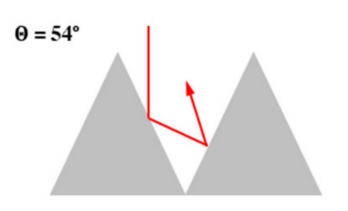

$30^{\circ}<\theta<45^{\circ}$

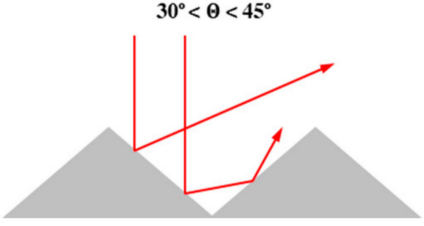

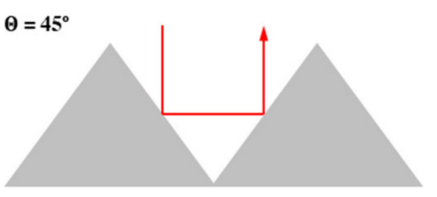

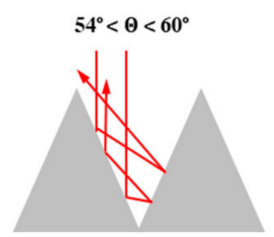

Figure 1. The path of light incident on the V-shaped surface according to angle.

Accordingly, increasing the absorption of light through the number of reflections can be directly related to the efficiency of the solar cell, so that the degree of curvature formed on the surface can contribute to the improvement of the efficiency of the solar cell. A solar cell having a micro-sized pyramid structure can control the average reflectance to less than $10 \%$, and a solar cell having a nano-sized pyramid structure can improve short-circuit current by reducing reflectance [12]. There are methods of forming various wafer surfaces, such as a micro-sized pyramid structures and nano-sized pyramid structures. Methods for forming micro-sized pyramid structures include alkali solution etching, reactive ion etching (RIE), and metal-assisted chemical etching (MACE). The pyramid formation method using an alkali such as $\mathrm{NaOH}$ and $\mathrm{KOH}$ solutions is the most widely used, and anisotropic etching is performed according to the crystal orientation of the c-Si solar cell. Dissolving a specific surface faster than other surfaces is called anisotropic etching or anisotropic etching. Anisotropic etching is mainly used for the surface treatment of single c-Si wafers, and an alkali solution of sodium hydroxide $(\mathrm{NaOH})$ and potassium hydroxide $(\mathrm{KOH})$ is used. The mechanism of anisotropic etching is as follows. The Si surface is oxidized by $\mathrm{OH}^{-}$ions, and sodium silicate $\left(\mathrm{K}_{2} \mathrm{SiO}_{3}\right)$ is formed through combination with $\mathrm{K}^{+}$and $\mathrm{Na}^{+}$ ions [13]. RIE is a method of etching by simultaneously performing physical collisions and chemical reactions caused by plasma [14]. During the etching reaction by plasma, radicals and ions are adsorbed on the surface of the Si wafer, and a reactant is formed through a chemical reaction. The formed reactants are desorbed, and the desorbed reactants are discharged out of the chamber. The gases used for etching are Si etching gases, such as $\mathrm{Cl}_{2}$ and $\mathrm{SF}_{6}$, which are difficult to manage due to toxicity and explosion characteristics. For this reason, processes using $\mathrm{SF}_{6}$ and $\mathrm{O}_{2}$ gases, which are relatively easy to manage and non-toxic fluorine gases, are widely used. At this time, $\mathrm{SF}_{6}$ is composed of neutrons, electrons, photons, radicals $\left(\mathrm{F}^{*}\right)$, cations $\left(\mathrm{SF}^{5+}\right)$, and anions $\left(\mathrm{F}^{-}\right) . \mathrm{O}_{2}$ is composed of radicals $\left(\mathrm{O}^{*}\right)$, and glow discharge is generated by the dissociation and ionization of electron collisions. The MACE is an etching method using a metal catalyst such as $\mathrm{Ag}$ or $\mathrm{Cu}$. An oxidation reaction occurs at the interface between the silicon surface and the deposited metal catalyst, and a cathode reaction occurs where the metal and the solution exist [15-17]. In this paper, pyramid shapes of various sizes were implemented onto the wafer by using various etching processes such as etching using an alkaline solution, reactive ion etching, and metal-assisted chemical etching. Accordingly, when the optical loss through the reduction of the wafer's reflectance was minimized by using various etching processes, we studied how all cell characteristics were affected. The paper is written in two parts. The first section regards the surface etching process optimization according to various methods, and the second section outlines the effects of the doping layer according to the surface structure of the wafer. In the first topic, the influence of the doping layer according to various surface textures was comparatively analyzed. As was expected, the cell characteristics had a greater effect on the doping layer than on the electrode and surface passivation. The doping layer was formed through use of a furnace according to the surface structure of the wafer, and a comparative analysis was conducted. The second topic regards the analysis method of the doping layer. It is very important to measure the profile of the doping concentration distribution and doping depth after the emitter 
formation process. In general, doping profile is mainly measured using SIMS (secondary ion mass spectroscopy), ECV (electrochemical capacitance-voltage), or KFM (Kelvin probe force microscope) analysis methods. In this paper, instead of the SIMS, ECV, and KFM analysis methods, a selective etching method (SE) for analysis using a scanning electron microscope (SEM) was performed to analyze the doped layer after forming a step by using the difference in etching rate between the emitter layer and the non-emitter layer. Accordingly, compared to existing analysis methods, the doped layer can be analyzed using an easier and cheaper solution such as $\mathrm{HF}, \mathrm{H}_{2} \mathrm{O}_{2}$, or $\mathrm{H}_{2} \mathrm{O}$.

\section{Materials and Methods}

In order to analyze the cell characteristics according to the pyramidal structure by performing various surface etching, a p-type single c-Si wafer of $15.675 \times 15.675 \mathrm{~cm}^{2}$ was used. First, to remove impurities from the wafer substrate before performing the surface etching, ultrasonic cleaning was performed for $10 \mathrm{~min}$ in the order of acetone, methanol, and DI water. After removing metal impurities with a $10 \% \mathrm{HCl}$ solution and removing the natural oxide film with a $10 \% \mathrm{HF}$ solution, the wafer was sufficiently washed with DI water and then dried with nitrogen. After performing the wafer cleaning process, the etching process was carried out through five etching methods. The surface etching processes included a surface etching process using an alkali solution of $\mathrm{KOH}$, an etching process using RIE, an etching process using a Ag metal catalyst, and an etching process using two-step processes involving an alkali solution, RIE, and MACE. First, before proceeding with the wafer etching process, this process was performed after removing the surface cutting defects on the wafer surface using a $\mathrm{KOH}$ solution. Etching with an alkali solution, mainly $\mathrm{KOH}$, was used for the surface treatment of the single c-Si wafers. In order to proceed, the etching process with alkali solution, $\mathrm{KOH}, \mathrm{IPA}$, and DI water was used. The etching process conditions were changed at 2 to $3 \mathrm{wt} \%$ of $\mathrm{KOH}, 7.5$ to 9 vol.\% of IPA, and a process temperature of $80{ }^{\circ} \mathrm{C}$ to form a micro-sized pyramid on the surface [18]. The etching process using RIE was performed by forming a plasma using $\mathrm{SF}_{6}$ and $\mathrm{O}_{2}$ gases, which are fluorine gases, and using a chemical reaction with a Si wafer [19]. In the RIE process, the surface shape and reflectance characteristics of the wafer were analyzed by varying the gas ratio of $\mathrm{SF}_{6}$ and $\mathrm{O}_{2}$ from 5:1 to 1:2 and the etching time from 200 to $700 \mathrm{~s}$. In the MACE process, a Ag metal catalyst is deposited on the Si surface and then immersed in a solution mixed with $\mathrm{HF}$ and $\mathrm{H}_{2} \mathrm{O}_{2}$ to etch using oxidation and reduction reactions occurring between the $\mathrm{Si}$ substrate and the metal particles [15]. As the metal catalyst, Ag metal particles having a thickness of $7 \mathrm{~nm}$ were deposited on the surface of a Si wafer using a thermal evaporator. After the deposition step, in order to observe any changes according to the etching time, the Si wafer deposited the Ag metal particles and was etched under the conditions of 30 to $360 \mathrm{~s}$. Thereafter, after fixing the etching time, the characteristics of the wafer were analyzed by varying the ratio of the etching solutions. The etching process using $\mathrm{KOH}$ and RIE is an additional application of the RIE process utilized to form a nano-sized pyramid structure on wafer surfaces etched with $\mathrm{KOH}$. In the etching process using $\mathrm{KOH}$ and $\mathrm{MACE}$, a nano-structured pyramid is formed on a wafer surface-etched with $\mathrm{KOH}$ using a Ag metal catalyst. After forming a pyramid structure on the wafer surface using the five methods, the average reflectance of the wavelength of 400 1000 nm was measured with a UV/VIR spectrometer, and the pyramid structure was confirmed through field emission scanning electron microscope (FE-SEM) images [20]. In order to analyze the characteristics according to the pyramid structure when fabricating the wafer surface-etched through five methods into cells, an emitter formation process was performed using a furnace. In order to analyze the effects of the pyramid structure formed on the wafer on the emitter formation process, $\mathrm{POCl}_{3}$ gas was introduced into the furnace using a $\mathrm{POCl}_{3}$ liquid source as raw material. After pre-deposition at a temperature of $825^{\circ} \mathrm{C}$ on the surface of the substrate, this was diffused through high temperature heat of $845^{\circ} \mathrm{C}[21,22]$. Subsequently, the structural analysis in which the emitter layer was formed according to the pyramid structure was performed through SEM images, and quantum 
efficiency characteristics were compared to proceed with the electrical analysis based on the structural analysis of the emitter layer according to the pyramid structure

\section{Results}

The surface etching process was divided into a one-step process and a two-step process. The one-step etching process was performed through three methods: etching with alkali solution, in this case a $\mathrm{KOH}$ solution, etching with MACE, and etching with RIE. The two-step etching process was carried out through two methods: etching using an alkali solution and MACE, and etching using an alkali solution and RIE. Before the etching process began, saw damage to the bare wafer was removed by using $\mathrm{KOH}$ solution. Figure 2 shows the cross-section images of the bare wafer before the surface etching process and after the SDR process. The SDR process using a $\mathrm{KOH}$ solution was performed at a process temperature of $70{ }^{\circ} \mathrm{C}$ and a process time of $20 \mathrm{~min}$. The bare wafer had a reflectance of $30.18 \%$ and the SDR wafer had a reflectance of $31.89 \%$.

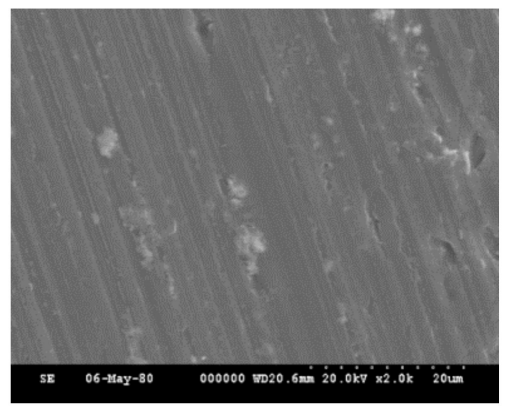

(a)

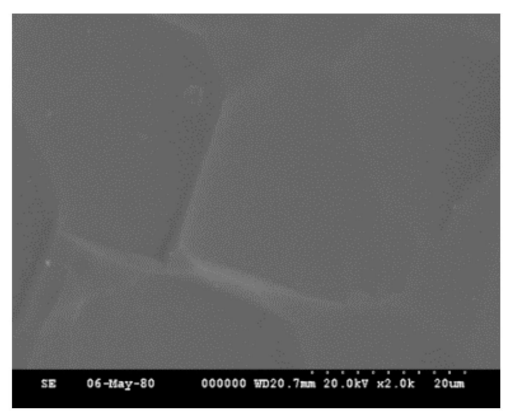

(b)

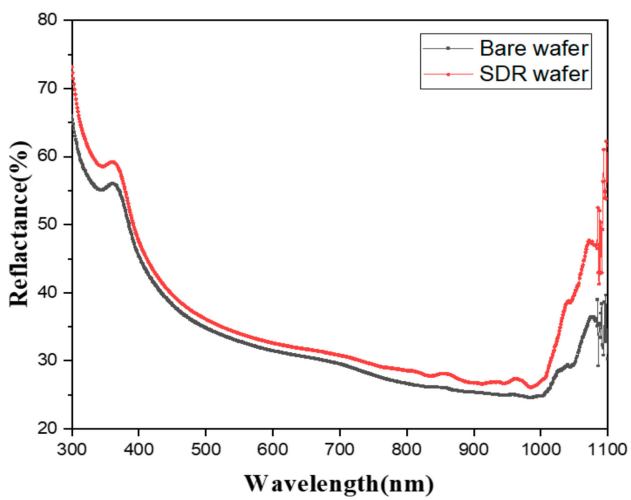

(c)

Figure 2. Cross-sectional SEM images of the c-Si wafer before and after the SDR process: (a) c-Si wafer before the SDR process, (b) c-Si wafer after the SDR process, and (c) reflectance of the c-Si wafer before and after the SDR process.

\subsection{Conventional Etching (Alkali Solution)}

The pyramid formation method using an alkali solution is most commonly used, but has a limitation in that it cannot obtain specific angles. Accordingly, it is possible to observe the characteristics of the reflectance for each wavelength according to the change of the pyramid size rather than the change of the pyramid angle. In this study, the structural and optical properties of the pyramid were analyzed using $\mathrm{KOH}$ as alkali solution to form the structure of the micro pyramid. The approximate etching depth for the surface etching of a single crystal $\mathrm{Si}$ wafer can be calculated by the following equation using the etching weight of the wafer:

$$
\text { Etching Depth }=\frac{\text { Etching Weight }(\mathrm{g})}{\text { Silicon Density }\left(\mathrm{g} / \mathrm{cm}^{3}\right) \times \text { Wafer Area }\left(\mathrm{cm}^{2}\right)} \times \frac{1}{2}
$$

The etching weight represents a value obtained by subtracting the weight of the wafer after etching from the weight of the wafer before etching, and the Si density was calculated by applying the Si density value of $2.33 \mathrm{~g} / \mathrm{cm}^{3}$ at room temperature. In the surface etching using $\mathrm{KOH}$, both sides of the wafer are etched at the same time, so the approximate etching depth is half of the total etched amount. Through the above equation, the etching depth of the wafer according to the $\mathrm{KOH}$ and IPA concentrations is expressed as shown in Figure 3a. As the $\mathrm{KOH}$ concentration increases, the etching depth generated at the same time increases, because the etching rate increases as the $\mathrm{KOH}$ concentration increases. As the etch rate increases, the size of the hydrogen droplet increases quickly, making it difficult to form a pyramid on the surface, and pyramid uniformity is lower with a higher concentration. As the concentration of the IPA increases, the etching depth tends 
to decrease, which seems to make the concentration of $\mathrm{KOH}$ in the $\mathrm{H}_{2} \mathrm{O}$ lower. However, in practice, IPA acts as a surfactant, reducing the surface tension of the solution and removing hydrogen droplets. Accordingly, rather than lowering the concentration, it acts as a factor that interferes with the etching reaction by lowering the etching rate on the surface. In addition, since IPA takes away the heat of the reaction to vaporize, etching is slow and the pyramid is not formed, and accordingly, it was confirmed that the size of the pyramid cannot be increased $[23,24]$.

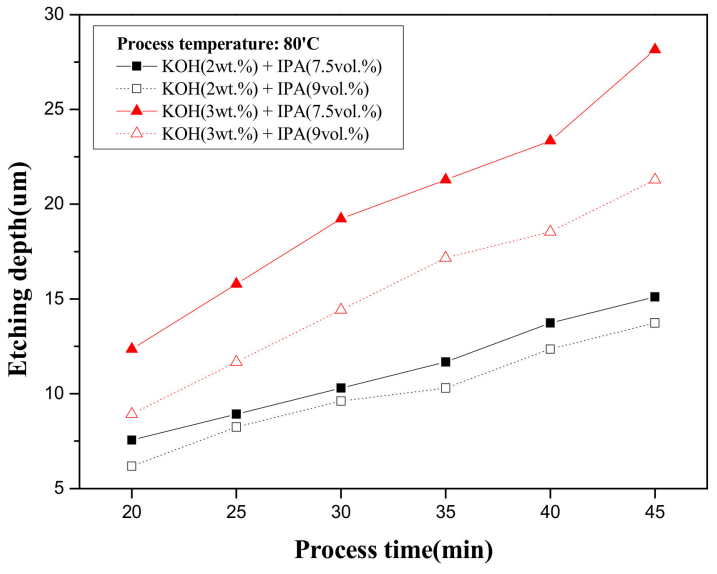

(a)

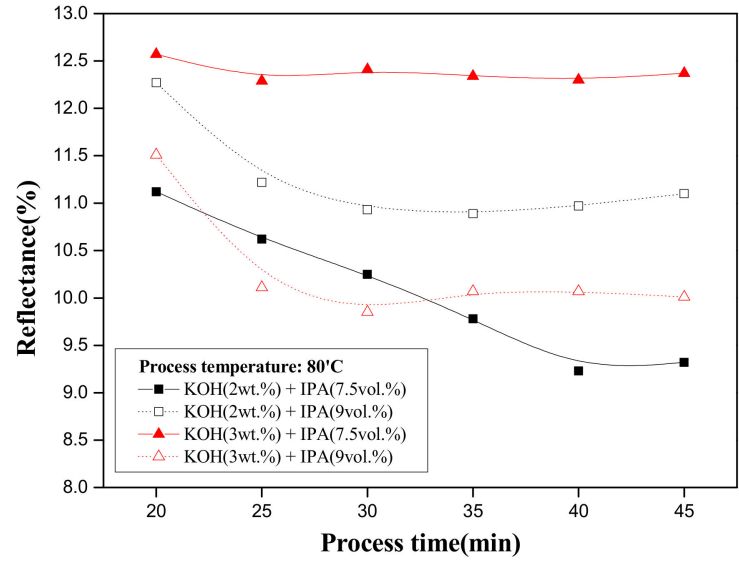

(b)

Figure 3. Characteristics of the wafer according to the $\mathrm{KOH}$ and IPA concentrations: (a) etching depth and (b) reflectance.

Figure $3 \mathrm{~b}$ shows the reflectances of the wafer according to the concentrations of solutions such as $\mathrm{KOH}$ and IPA. Figure 4 shows the SEM images of the wafer surface according to the concentrations of solutions such as $\mathrm{KOH}$ and IPA. In the above experiment, $\mathrm{KOH}$ concentration plays a leading role in the formation of the pyramid, and IPA helps the formation of the pyramid under the proper concentration conditions, but when the concentration of IPA increases, a non-uniform pyramid showing high reflectance is formed. It was confirmed that the size of the pyramid increased as the concentration of $\mathrm{KOH}$ increased, and it was observed that the reflectance greatly decreased with IPA concentrations of 7.5\% and $9 \%$ in conditions of the $\mathrm{KOH}$ concentrations of $2 \%$ and $3 \%$, respectively. When the $\mathrm{KOH}$ concentration was $2 \%$, if the IPA concentration increases from 7.5 to $9 \%$, the size of the pyramid was very non-uniform and the reflectance was increased. In a pyramid structure having a uniform size, the reflected light is relatively constant, but in a pyramid structure with a large difference, light is not reflected, and the reflectance increases. The highest reflectance was confirmed under the conditions of a $\mathrm{KOH}$ concentration of $3 \%$ and IPA concentration of $7.5 \%$. This is because the pyramid formed initially at a fast etching rate grows large, and the pyramid formed later grows smaller due to the slow etching rate. Accordingly, as the $\mathrm{KOH}$ concentration increases, the pyramid size becomes nonuniform. It can be seen that as the pyramid size increases, the uniformity of the pyramid size decreases.

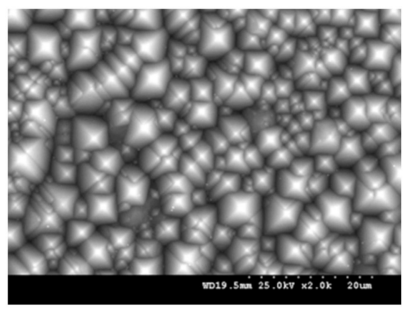

(a)

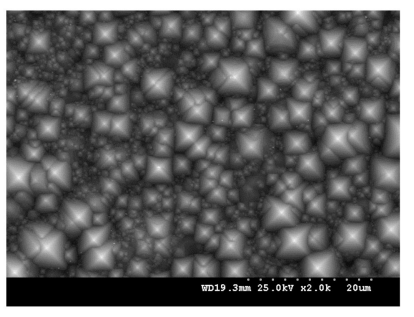

(b)

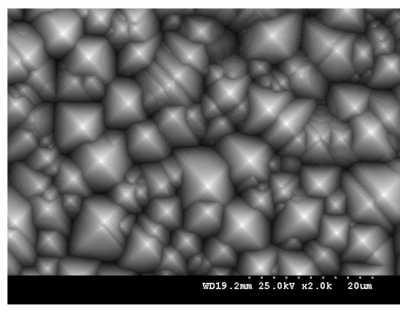

(c)

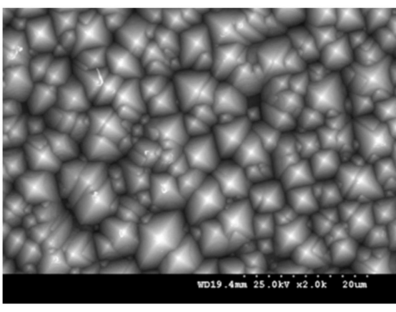

(d)

Figure 4. SEM images of wafer surface according to $\mathrm{KOH}$ and IPA concentrations: (a) $\mathrm{KOH} 2 \mathrm{wt}$. \%, IPA 7.5 vol. $\%$; (b) $\mathrm{KOH}$ 2 wt.\%, IPA 9 vol. \%; (c) KOH 3 wt.\%, IPA 7.5 vol.\%; and (d) KOH 3 wt.\%, IPA 9 vol.\%. 


\subsection{Metal-Assisted Chemical Etching (MACE)}

Etching processes using a metal catalyst rely on the reduction of the oxidizing agent by the catalyst causing $\mathrm{Si}$ atoms near the deposited metal catalyst and the Si interface to be etched, taking into account that the metal catalyst penetrates the Si substrate in a vertical direction, thereby generating pores. The MACE process greatly affects the etching shape and reflectance characteristics of the wafer depending on conditions such as the type of metal catalyst, the deposition thickness of the metal catalyst, the ratio of the etching solution, and the etching time. Among them, process factors such as the ratio of the etching solution based on $\mathrm{HF}$ and $\mathrm{H}_{2} \mathrm{O}_{2}$ and the etching time control the etching rate to change the shape of the pores of the $\mathrm{Si}$ wafer. Accordingly, nano-pyramidal structures having various sizes and shapes can be obtained. In this study, a nano-pyramidal structure was formed through a surface texture process using a Ag metal catalyst, and the effects of the etching conditions on the wafer shape were analyzed.

Figure 5 shows reflectance and cross-section SEM images of the wafer surface according to etching time for the MACE process. At an etch time of $30 \mathrm{~s}$, it was confirmed that the pore depth was $99 \mathrm{~nm}$. Here, it was considered that the etching process had proceeded, however a relatively high reflectance characteristic of $10.12 \%$ was demonstrated. This is because the etching time of $30 \mathrm{~s}$ was too short, and it was not sufficient to create pores. It was confirmed that the pore depth rapidly increased from etching times of $90 \mathrm{~s}$ or more, with reflectance values decreasing to $5 \%$ or less. As the etching time increased, an oxide film as $\mathrm{SiO}_{2}$ was formed at the interface between the $\mathrm{Si}$ wafer and the metal particle and was etched by HF, through which the metal particles entered to form a deeper structure. Since the reaction rate was affected by the ratio of the etching solution rather than the etching time, the etching time was fixed at $180 \mathrm{~s}$ (s), the condition showing the lowest reflectance, and then the characteristics of the etched wafer were analyzed by varying the ratio of the etching solution. The ratio of the etching solution can be expressed as a mole fraction, and $\rho$ can be expressed as the following equation:

$$
\rho=(\mathrm{HF}) /\left(\mathrm{HF}+\mathrm{H}_{2} \mathrm{O}_{2}\right)
$$
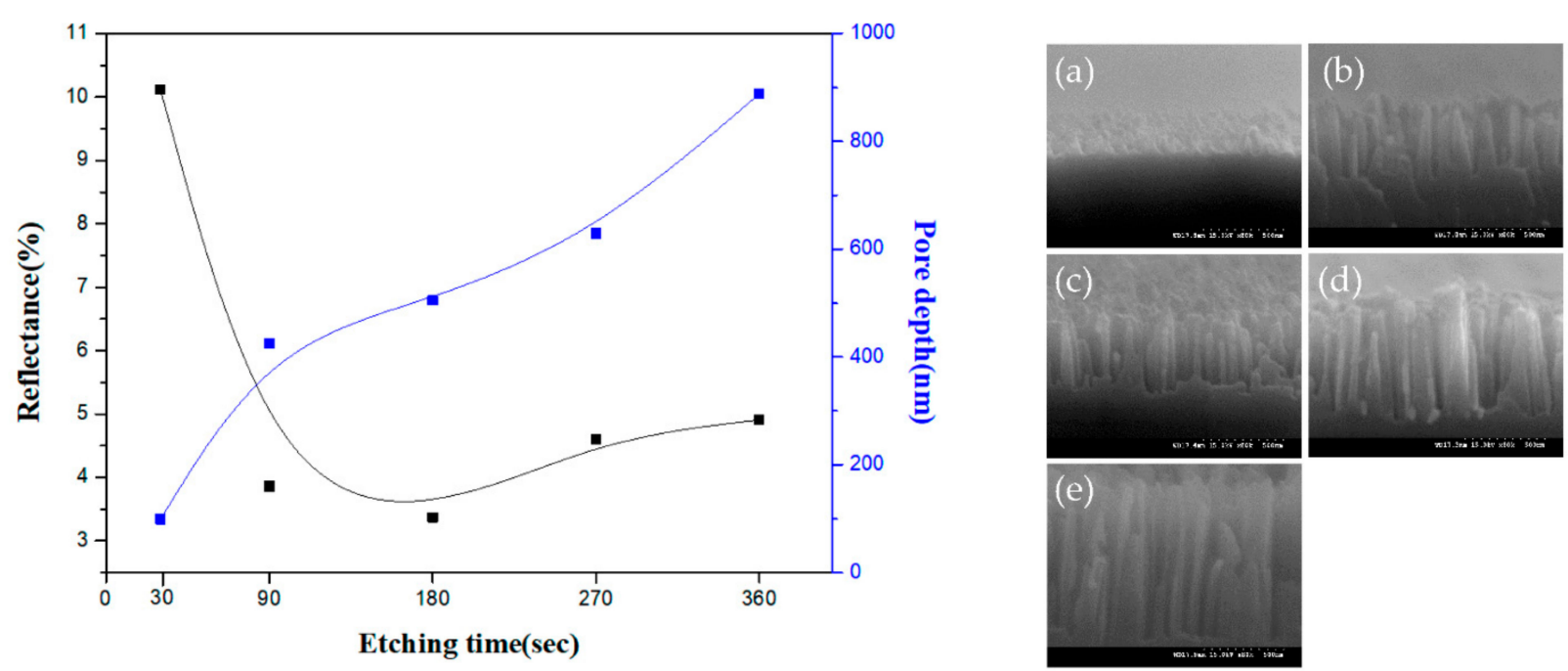

Figure 5. Reflectance and cross-section SEM images of wafer surfaces according to etching times for the MACE process: (a) $30 \mathrm{~s}$, (b) $90 \mathrm{~s}$, (c) $180 \mathrm{~s},(\mathbf{d}) 270 \mathrm{~s}$, and (e) $360 \mathrm{~s}$.

As shown in the above equation, a larger $\rho$ value indicates that the HF concentration is relatively high, whereas a smaller $\rho$ value indicates that the $\mathrm{H}_{2} \mathrm{O}_{2}$ concentration is relatively high. In this paper, an experiment was conducted by varying the value of $\rho$ from 0 to $100 \%$, and the characteristics of the wafer were analyzed. Figure 6 shows the reflectance and cross-section SEM images of the wafer surfaces according to mole fraction $(\rho)$ for the MACE process. It can be seen that the etching process did not proceed, as the reflectance of 
the wafer was similar to that of the initial reflectance until the $\rho$ condition of $30 \%$. This is because the content of $\mathrm{HF}$ for etching $\mathrm{SiO}_{2}$ was too low, thus the etching was not sufficiently performed. The reflectance decreased from the condition of $\rho 40 \%$, but remained relatively high. Under the condition of $\rho 100 \%$, there was no $\mathrm{H}_{2} \mathrm{O}_{2}$ reduction process because only HF exists in the solution. Accordingly, it was confirmed that the etching process was not performed because the $\mathrm{SiO}_{2}$ layer could not be generated. From the condition of $\rho 80 \%$, the reflectance was rapidly decreased. In order to analyze this, a structural analysis of the wafer after the etching process was performed through SEM images. As shown in Figure 6, the surface shape of the wafer was very different depending on the value of $\rho$, and in the range of $80 \%<\rho<90 \%$, a deep pore shape of $500 \mathrm{~nm}$ or more could be observed. In the range of $\rho<70 \%$, pores were not observed, but it was observed that the wafer surface was etched non-uniformly. The formation of deep pores is determined by the reaction rate by the reduction reaction of $\mathrm{H}_{2} \mathrm{O}_{2}$. When the $\rho$ value is large, the $\mathrm{H}_{2} \mathrm{O}_{2}$ reduction proceeds slowly because the HF ratio is high. The electrons required for $\mathrm{H}_{2} \mathrm{O}_{2}$ reduction are sufficiently procured from the local region of the metal catalyst and the Si interface. Accordingly, the Si wafer placed under the catalyst particles is etched to form deep and vertical pores. As a result, the surface reflectance of the etched wafer after the MACE process was the lowest at $2.36 \%$ under the condition of $\rho$ of 0.9 .
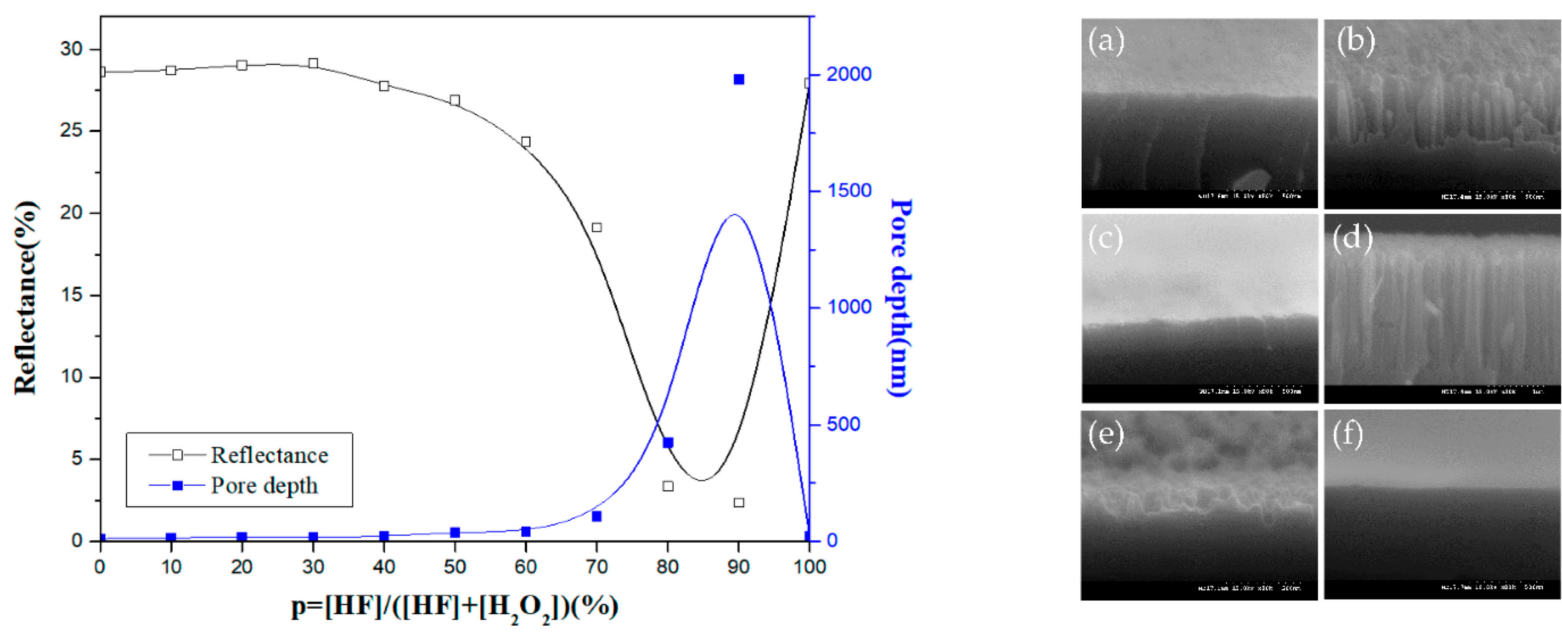

Figure 6. Reflectance and cross-section SEM images of wafer surfaces according to mole fraction ( $\rho$ ) for the MACE process: (a) $\rho 50 \%$, (b) $\rho 60 \%$, (c) $\rho 70 \%$, (d) $\rho 80 \%$, (e) $\rho 90 \%$, and (f) $\rho 100 \%$.

\subsection{Reactive Ion Etching (RIE)}

In this study, a one-step surface etching process was performed using RIE, and the effect of the process conditions of gas ratio and process time on the shape and reflectance characteristics of the wafer after etching was analyzed. In the RIE process, the gas ratio of $\mathrm{SF}_{6}$ and $\mathrm{O}_{2}$ acts as an important factor in determining the shape and size of the pyramid, and has a great influence on the reflectance characteristics. The pyramid structures of various sizes are formed according to the gas ratio, which is related to the density of the $\mathrm{Si}_{\mathrm{x}} \mathrm{O}_{\mathrm{y}} \mathrm{F}_{\mathrm{z}}$ passivation occurring in the initial process. The introduced $\mathrm{SF}_{6}$ and $\mathrm{O}_{2}$ generate radicals of $\mathrm{F}^{*}$ and $\mathrm{O}^{*}$ by plasma, and the etching rate varies depending on the ratio of these radicals. At this time, the $\mathrm{Si}_{\mathrm{x}} \mathrm{O}_{\mathrm{y}} \mathrm{F}_{\mathrm{z}}$ layer formation rate formed on the sidewall can be expressed as $v_{p f}$, and the etching rate of the etched $\mathrm{Si}_{x} \mathrm{O}_{y} \mathrm{~F}_{z}$ passivation can be expressed as $v_{\text {pe }}$. The etching rate of the Si wafer can be expressed as $v_{\mathrm{Si}}$. Etching is not performed when $v_{\text {pe }}$ is low and $v_{\text {pf }}$ is high, whereas when high $v_{\text {pe }}$ and low $v_{\text {pf }}$ exist a uniform etching shape instead of a pyramid structure is shown. It was confirmed that in the case of low $v_{\text {pe }}$ and high $v_{\mathrm{pf}}$, the $\mathrm{Si}_{\mathrm{x}} \mathrm{O}_{\mathrm{y}} \mathrm{F}_{\mathrm{z}}$ passivation was excessively deposited on the wafer surface, and in the case of high $v_{p e}$ and low $v_{p f}$, the $\mathrm{Si}_{x} \mathrm{O}_{y} \mathrm{~F}_{z}$ passivation was not sufficiently deposited. That is, the $\mathrm{Si}_{\mathrm{x}} \mathrm{O}_{\mathrm{y}} \mathrm{F}_{\mathrm{z}}$ passivation serves to help the $\mathrm{Si}$ wafer to be partially etched because it interferes with the etching by $\mathrm{F}^{*}$ radicals on its side. Through this process, the etching shape 
can be controlled. Figures 7 and 8 show the surface shape and reflectance characteristics of the wafer according to the gas ratio and etching time after RIE etching. As shown in Figure 7, different shapes of pyramids can be observed depending on the different ratios of $\mathrm{SF}_{6}$ and $\mathrm{O}_{2}$. It was confirmed when the ratio of $\mathrm{O}_{2}$ was higher, a pyramid structure with the low aspect ratio was obtained, and the reflectance also increased. When $\mathrm{SF}_{6}$ and $\mathrm{O}_{2}$ gas were added at an appropriate ratio, the surface shape may be small and densely generated, resulting in low reflectance, but when the $\mathrm{O}_{2}$ gas ratio was excessively injected, the mask role was too strong and the surface was etched too little, so that the reflectance increased. As a result, the lowest reflectance of $5.92 \%$ was confirmed under the gas ratio of $\mathrm{SF}_{6}$ and $\mathrm{O}_{2}$ of 1:3. After fixing the gas ratio to $\mathrm{SF}_{6}$ and $\mathrm{O}_{2}$ of $1: 2$, the experiment was conducted by varying the process time from 200 to $700 \mathrm{~s}$ to analyze the effect of the process time. As shown in Figure 8, when the process time was 200 s, a high reflectance of $14.42 \%$ was confirmed because the etching rate did not increase sufficiently. It was confirmed that the reflectance of the wafer gradually decreased through the increased etching rate under a process time of $300 \mathrm{~s}$. Under process time conditions of $400 \mathrm{~s}$ or more, the reflectance of wafer was less than approximately $5 \%$. It was confirmed that at the process times of $600 \mathrm{~s}$ or more, the size of the pyramid no longer increased even if the process time was increased, and the reflectance also reached a limit and did not decrease any more. As a result, the lowest reflectance of $3.87 \%$ was shown under the process time of $400 \mathrm{~s}$.
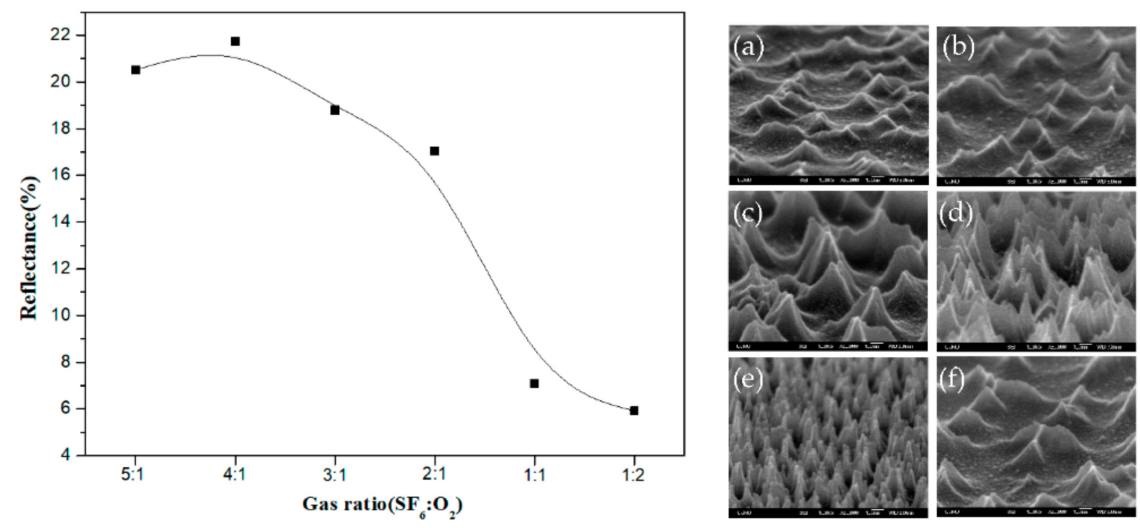

Figure 7. Reflectance and cross-section SEM images of wafer surfaces according to gas ratio for the RIE process: (a) $\mathrm{SF}_{6}: \mathrm{O}_{2}=5: 1,\left(\right.$ b) $\mathrm{SF}_{6}: \mathrm{O}_{2}=4: 1$, (c) $\mathrm{SF}_{6}: \mathrm{O}_{2}=3: 1$, (d) $\mathrm{SF}_{6}: \mathrm{O}_{2}=2: 1$, (e) $\mathrm{SF}_{6}: \mathrm{O}_{2}=1: 1$, and (f) $\mathrm{SF}_{6}: \mathrm{O}_{2}=1: 2$.
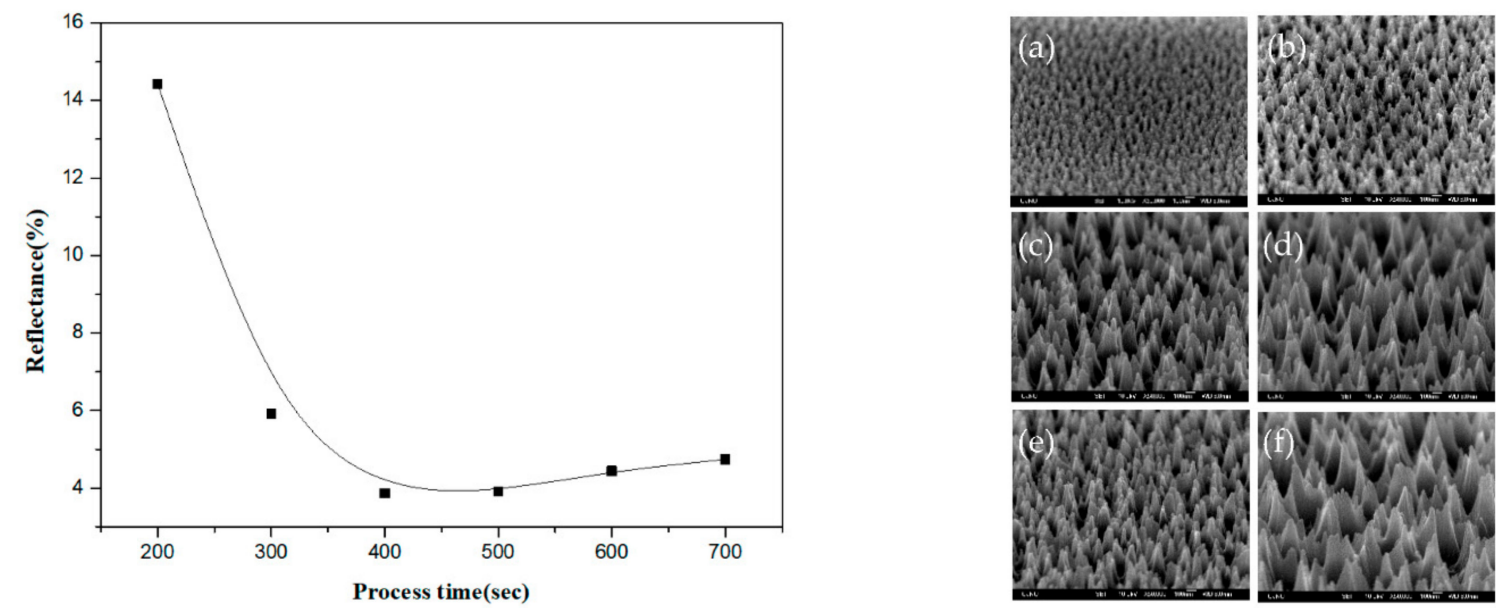

Figure 8. Reflectance and cross-section SEM images of wafer surfaces according to etching time for the RIE process: (a) $200 \mathrm{~s}$, (b) $300 \mathrm{~s}$, (c) $400 \mathrm{~s}$, (d) $500 \mathrm{~s}$, (e) $600 \mathrm{~s}$, and (f) $700 \mathrm{~s}$. 


\subsection{Metal-Assisted Chemical Etching Alkali Solution Etching (Alkali Solution + MACE)}

In the previous experiment, a one-step etching process was performed using $\mathrm{KOH}$, which is an alkali solution. Through this, it was possible to lower the reflectance from about $30 \%$, which is the initial reflectance of the wafer, to $9.11 \%$. After the one-step etching process was performed, a two-step etching process was performed with the MACE process. The two-step etching process was divided into two stages of deposition and etching, the same as the one-step etching process using MACE. After the deposition of the Ag metal catalyst through a thermal evaporator, a Si wafer-deposited Ag metal was immersed in a solution of a mixture of a solution containing fluorine (F) such as HF and an oxidizing agent such as $\mathrm{H}_{2} \mathrm{O}_{2}$ to be etched. In this study, the effect on the thickness of the Ag metal catalyst used in the deposition step and the effect of the etching solution ratio in the etching step were analyzed. First, the Ag metal catalyst thickness was fixed to a constant value, and then the effect of the etching solution ratio was analyzed. The thickness of the Ag metal catalyst was fixed to $7 \mathrm{~nm}$, and the etching time was fixed to $3 \mathrm{~min}$ in various ratios of etching solution in order to observe the change. The concentration of HF in the etching solution was fixed to $1 \mathrm{M}$, and the experiment was conducted by increasing the molar ratio of $\mathrm{H}_{2} \mathrm{O}_{2}$, which was converted into a $\rho$ as mole fraction. The etching reaction rate was determined by the reduction reaction of $\mathrm{H}_{2} \mathrm{O}_{2}$, which means that when concentration of $\mathrm{HF}$ is greater than the ratio of $\mathrm{H}_{2} \mathrm{O}_{2}$, the $\mathrm{H}_{2} \mathrm{O}_{2}$ reduction proceeds slowly. Accordingly, it can be seen that the shape of the $\mathrm{Si}$ surface is very different after the surface etching process according to the $\rho$ of the etching solution. Figure 9 shows the reflectance and cross-section SEM images of wafer surfaces according to $\rho$ for the two-step etching process with alkali solution and MACE. As the $\rho$ value decreases, the reduction of $\mathrm{H}_{2} \mathrm{O}_{2}$ proceeds faster, and electrons required for this are supplied not only from the interface between the catalyst and the Si wafer, but also from the pore walls at a distance. Accordingly, not only the area under the metal catalyst particles, but also the pore walls of the $\mathrm{Si}$ wafer were etched, resulting in a shape of pores in which pore wall was inclined rather than vertical. As a result, a deep and uniform pore shape was displayed under the conditions of $\rho 50 \%$, and the lowest reflectance of approximately $1.62 \%$ was confirmed.
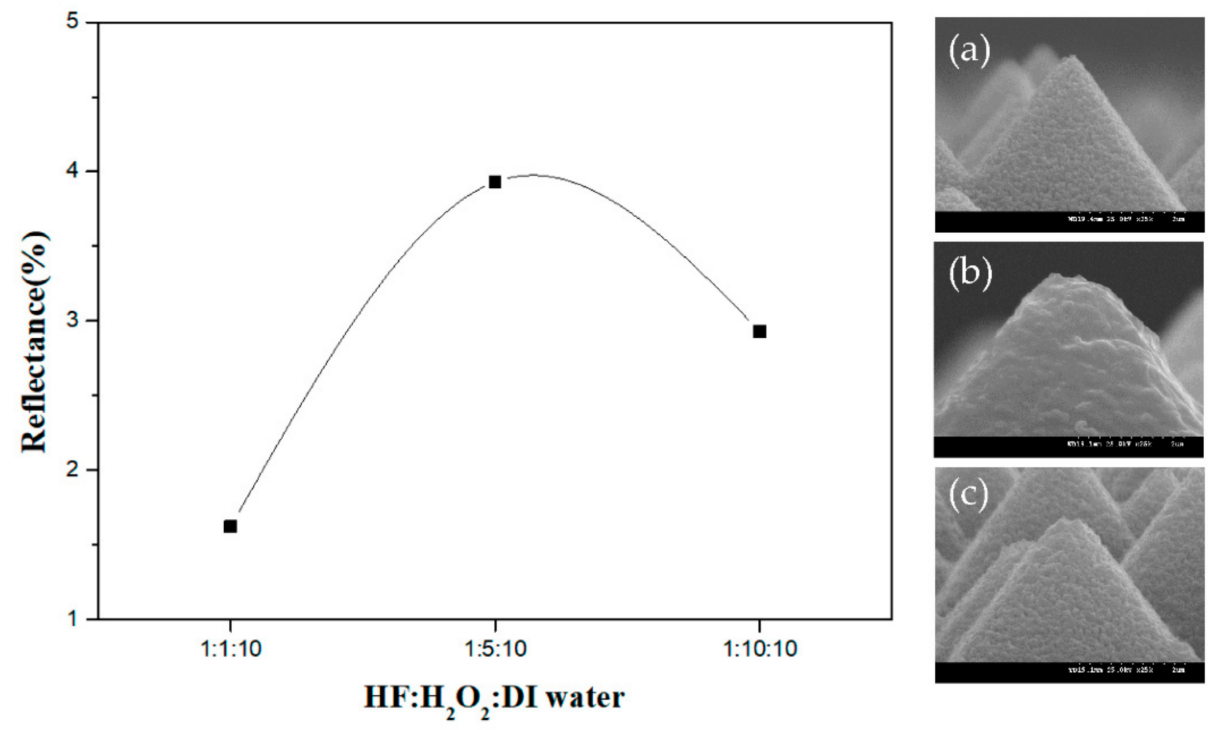

Figure 9. Reflectance and cross-section SEM images of wafer surfaces according to $\rho$ for the two-step etching process with alkali solution and MACE: (a) $\rho 50 \%$, (b) $\rho 16.6 \%$, and (c) $\rho 9.09 \%$.

As a result, the lowest reflectance was obtained under the conditions of a Ag metal catalyst thickness of $7 \mathrm{~nm}$, an etching time of $3 \mathrm{~min}$, and a $\rho 50 \%$. After the $\rho$ was fixed at $50 \%$, the thickness of the Ag metal catalyst was changed in the deposition step to observe its effect. When the thickness of the Ag metal catalyst was less than $5 \mathrm{~nm}$, the etching process was not performed smoothly. Accordingly, the thickness of the Ag metal catalyst was 
deposited at 7, 10, and $13 \mathrm{~nm}$. The etching was performed under conditions of 1 to $5 \mathrm{~min}$ for each thickness. Figure 10 shows the reflectance and cross-section SEM images of the wafer surfaces according to etching time for two-step etching process with alkali solution and MACE after depositing a Ag metal catalyst according to various thicknesses. The SEM image shows a cross-sectional image of a wafer after depositing a Ag catalyst of a thickness of $13 \mathrm{~nm}$ and etching according to the etching time. It was found that the reflectance results of the wafer were all within $5 \%$ of one another under the varying thickness conditions of Ag metal catalyst. When forming a nano-sized pyramid on a micro-sized pyramid structure formed using a $\mathrm{KOH}$ solution, reflectance gradually decreased as the etching time increased, showing the lowest reflectance of $1.3 \%$ in conditions of Ag thickness of $13 \mathrm{~nm}$. As the etching time increased, the depth of the nano-pyramid increased, so that the reflectance was decreased. This means that the better absorption of the incident light was allowed within the nano-pyramid structure of $\mathrm{Si}$. However, if the etching process is performed for more than $3 \mathrm{~min}$, the reflectance gradually increases. This is because as the etching time increases, the pyramid structure of the surface gradually collapses due to excessive etching, and accordingly, the reflectance increases due to the non-uniform characteristics of the wafer surface. As can be seen from Figure 10, since the size of the pores is determined by the size of the Ag metal particles in the deposition step before etching, it is important to deposit the Ag metal catalyst in the form of nano-particles. As a result of comparing the structural shape of the wafer according to the etching time, it can be seen that the nano-pyramid structure was not formed when etching at a thickness of $7 \mathrm{~nm}$ for $1 \mathrm{~min}$. This is because not all Ag particles reacted due to the short etching time. As the etching time gradually increased, the number of pores increased, and a dense structure of the surface of the Si wafer could be observed. This is because as the etching time increased, the oxide film formed at the interface between the Si wafer and the metal particles was etched by HF, and through this, the metal particles entered deeper to form deep and high pores. Accordingly, the shape of the pores is perpendicular to the Si surface, and the height and inclination of the structure affects reflectance, so it was confirmed that the reflectance decreases as the etching time increases [25,26]. However, after depositing the Ag metal catalyst of 10 to $13 \mathrm{~nm}$ thickness, it was confirmed that the pore depth was shallow and a non-uniform pore shape was confirmed under the etch time conditions of 5 min or more. This is because even though the Ag metal catalyst was sufficiently etched, excessive etching occurred with the longer etching time. Accordingly, etching happened not only in the area where the Ag catalyst was deposited but also in the area where the Ag metal catalyst was not formed, resulting in a deterioration of the surface characteristics. As a result, an etching time of 3 min was found to be optimal for the $13 \mathrm{~nm}$-thick Ag metal catalyst, and the lowest reflectance of approximately $1.3 \%$ was confirmed.
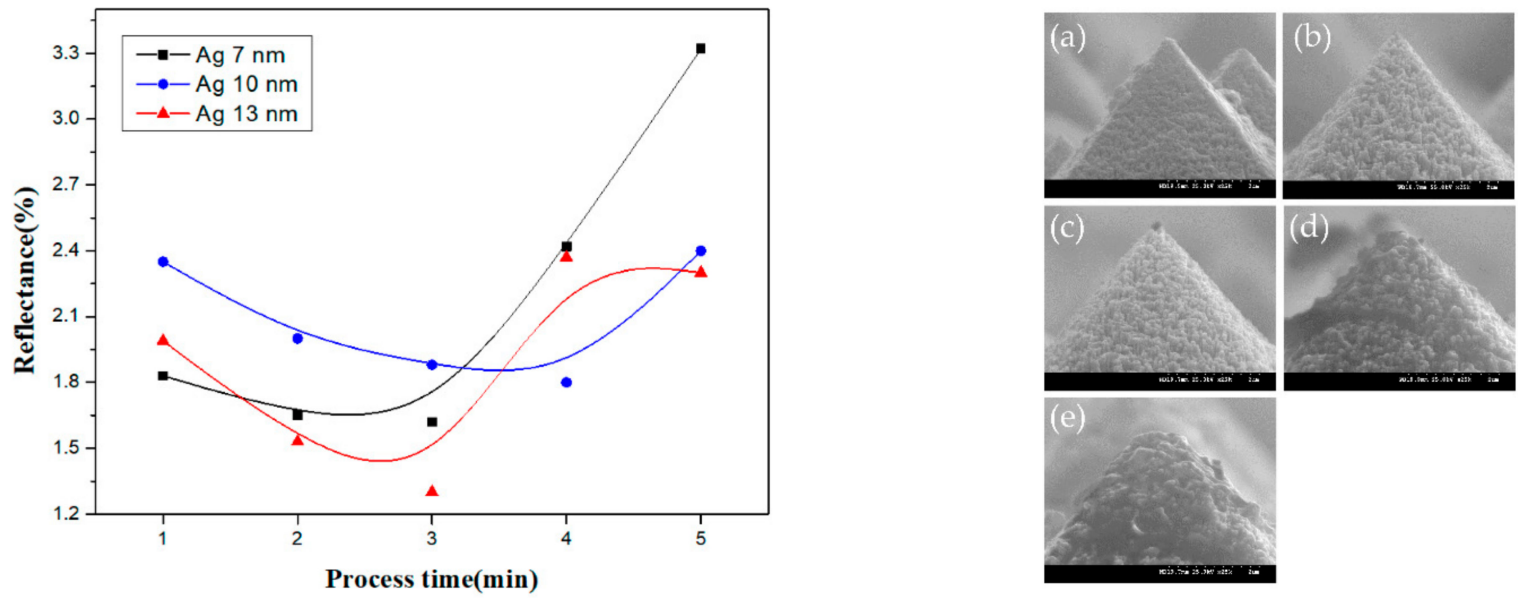

Figure 10. Reflectance and cross-section SEM images of wafer surfaces according to etching time for the two-step etching process with alkali solution and MACE after depositing a Ag metal catalyst according to various thicknesses: (a) 1 min, (b) $2 \mathrm{~min}$, (c) $3 \mathrm{~min},(\mathbf{d}) 4 \mathrm{~min}$, and (e) $5 \mathrm{~min}$. 
Metal removal was performed for $30 \mathrm{~min}$ in a solution in which $\mathrm{NH}_{3}$ and $\mathrm{H}_{2} \mathrm{O}_{2}$ were mixed in a ratio of 3:1 to remove any remaining Ag particles after the completion of the etching process. Figure 11 shows the energy dispersive X-ray spectroscopy (EDS) measurement results before and after removing the Ag particles. As shown in the Figure 11, it was confirmed that $\mathrm{Si}$ and Ag components appeared along with peaks after Ag deposition, and it was confirmed that all the particles of $\mathrm{Ag}$ were removed after etching.
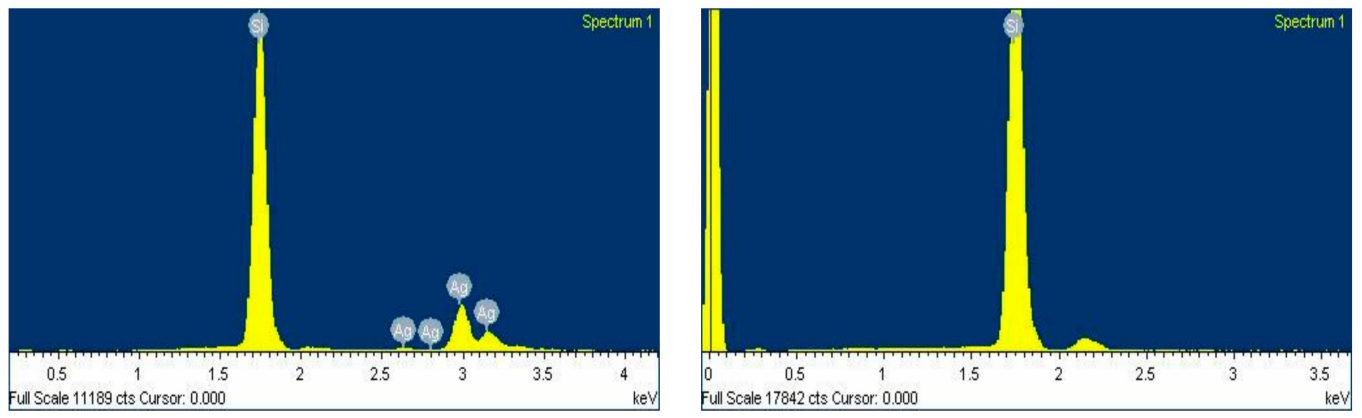

Figure 11. Energy dispersive X-ray spectroscopy (EDS) measurement results before and after removing Ag particles.

\subsection{Reactive Ion Etching with Alkali Solution Etching (Alkali Solution + RIE)}

A one-step surface etching process was performed using an alkali solution, and then a two-step surface etching process was performed using the etched wafer. $\mathrm{SF}_{6}$ gas, $\mathrm{O}_{2}$ gas, and Ar gas were used for the RIE process, and the effects of the gas ratio of $\mathrm{SF}_{6}$ and $\mathrm{O}_{2}$ and the RF power on the surface shape and reflectance characteristics of the wafer were analyzed. In the previous experiment with one-step etching process using RIE, the $\mathrm{F}$ radicals lead the etching and the $\mathrm{O}$ radicals passivated the $\mathrm{Si}$ wafer. As a result, the balance between etching and passivation induces vertical etching, and through this, as the etching time increases, the etching rate increases. In addition, as the etching proceeds for a longer period of time, the formation of a nano-pyramid structure can be observed, which is composed between the $\mathrm{Si}$ and $\mathrm{Si}_{\mathrm{x}} \mathrm{O}_{\mathrm{y}} \mathrm{F}_{\mathrm{z}}$ layers. Figure 12 shows the reflectance and cross-section SEM images of wafer surfaces according to the gas ratio for two-step etching process with alkali solution and RIE. When the ratio of $\mathrm{SF}_{6}$ and $\mathrm{O}_{2}$ was 3:1, an etching rate of $30.81 \mathrm{~nm} / \mathrm{min}$ was measured, and when the ratio of 2:1 was used this rate was $48.93 \mathrm{~nm} / \mathrm{min}$. However, the etching rate started to decrease from the ratio conditions of $\mathrm{SF}_{6}: \mathrm{O}_{2}$ at $1: 1$, and the etching rate was zero in the case of the 1:3 ratio, because no etching was performed at all. This can be seen from the chemical reaction equation of RIE dry etching in Equation (3) from Equation (7), given below:

$$
\begin{gathered}
S F_{6}(\text { gas })+A r^{*}(\text { gas }) \rightarrow S F_{6}(\text { gas })+F^{*}(\text { radical })+A r(\text { gas }) \\
\mathrm{O}_{2}(\text { gas })+A r^{*}(\text { gas }) \rightarrow S F_{6}(\text { gas })+\operatorname{Ar}(\text { gas }) \\
S F_{6}(\text { gas })+\mathrm{O}_{2}(\text { gas }) \rightarrow S F_{5} \mathrm{O} \\
4 F^{*}(\text { radical })+\mathrm{Si} \rightarrow S F_{4}(\text { gas }) \\
2 \mathrm{O}(\text { gas })+\mathrm{Si} \rightarrow \mathrm{SiO}_{2}(\text { solid })
\end{gathered}
$$



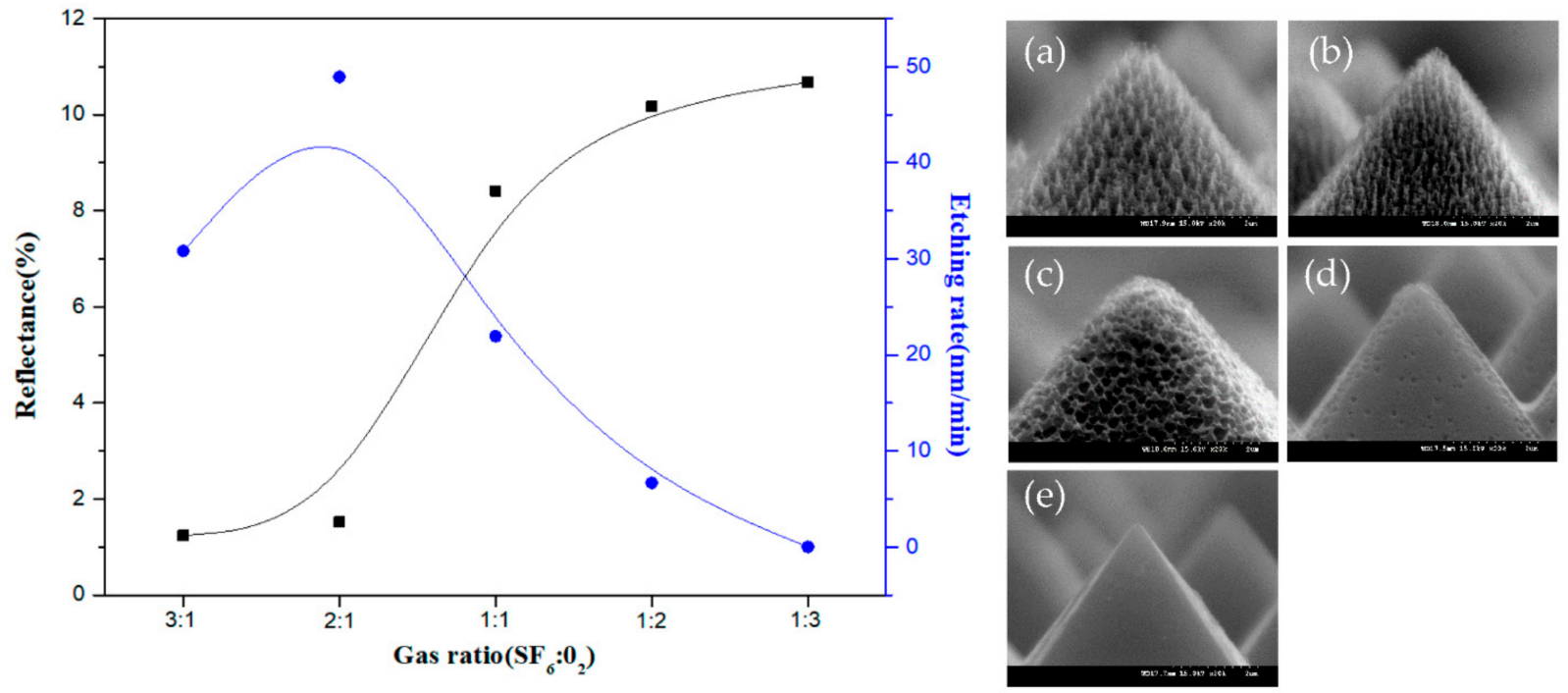

Figure 12. Reflectance and cross-section SEM images of wafer surfaces according to gas ratio for the two-step etching process with alkali solution and RIE: (a) $\mathrm{SF}_{6}: \mathrm{O}_{2}=3: 1$, (b) $\mathrm{SF}_{6}: \mathrm{O}_{2}=2: 1$, (c) $\mathrm{SF}_{6}: \mathrm{O}_{2}=1: 1$, (d) $\mathrm{SF}_{6}: \mathrm{O}_{2}=1: 2$, and (e) $\mathrm{SF}_{6}: \mathrm{O}_{2}=1: 3$.

The above equation represents the reactions of $\mathrm{SF}_{6}$ and $\mathrm{O}_{2}$ gas in the RIE process using plasma. As shown in Equations (3) and (6), fluorine radicals $\left(\mathrm{F}^{*}\right)$ are generated due to the physical collision of Ar gas and $\mathrm{SF}_{6}$ gas, and a chemical reaction between the $\mathrm{F}$ radicals and the $\mathrm{Si}$ wafer occurs. When the proportion of $\mathrm{SF}_{6}$ gas increases, the amount of $\mathrm{F}$ ions and $\mathrm{F}^{*}$ generated by collisions with $\mathrm{Ar}$ increases. The generated $\mathrm{F}$ ions and $\mathrm{F}$ radicals react directly with $\mathrm{Si}$ to generate $\mathrm{SF}_{4}$, which has volatile properties. On the other hand, when the proportion of $\mathrm{O}_{2}$ gas increases, the etching rate does not increase linearly. This can be seen through Equations (4) and (5). $\mathrm{SF}_{5}$ and $\mathrm{F}$ particles separated by Ar gas are chemically unstable, and recombine into $\mathrm{SF}_{6}$ within a short time. $\mathrm{SF}_{5} \mathrm{O}$ is formed by combining $\mathrm{O}_{2}$ with $\mathrm{SF}_{5}$ particles and temporarily prevents the reaction of $\mathrm{F}$ ions to recombine to $\mathrm{SF}_{6}$. Accordingly, until the ratio of $\mathrm{SF}_{6}$ and $\mathrm{O}_{2}$ becomes 3:1 to 2:1, the etching rate increases because the $\mathrm{O}_{2}$ gas contributes to the generation of $\mathrm{F}$ particles that directly react to the etching reaction. This can be seen from Equations (4) and (7). $\mathrm{O}_{2}$ gas is decomposed into monoatoms by plasma, and activated $\mathrm{O}$ atoms passivate the $\mathrm{Si}$ surface to form a thin film of $\mathrm{SiO}_{2}$ or $\mathrm{SiO}_{x}$ phase. Since the $\mathrm{SiO}_{2}$ thin film does not react with the $\mathrm{F}^{*}$ particles, the etching rate decreases as the $\mathrm{O}_{2}$ gas ratio increases As can be seen from Figure 12, Figure 12a shows the wafer surface with a densely formed nano-pyramidal due to the strong action of $\mathrm{F}$ radicals. Figure $12 \mathrm{c}$ shows that the entire wafer surface was etched. However, since the action of the $\mathrm{O}$ radical interferes with the etching, a pyramid surface shape with a low slope was obtained. As a result, under the ratio conditions of $\mathrm{SF}_{6}$ and $\mathrm{O}_{2}$ at 3:1, the reflectance greatly decreases due to the effect of the uniform and dense nano-pyramid, and a low reflectance of $1.24 \%$ was obtained.

Figure 13 shows the reflectance and cross-section SEM images of wafer surfaces according to RF power for the two-step etching process with alkali solution and RIE. The RF power was changed from 25 to $200 \mathrm{~W}$ while injecting the reaction gas. At an RF power of $50 \mathrm{~W}$ or less, a pyramid structure was not sufficiently formed on the surface because the physical collision of the reaction gas was weak. Accordingly, high reflectance values of $11.43 \%$ and $10.55 \%$ were confirmed respectively, and the etch rate was also less than approximately $7 \mathrm{~nm} / \mathrm{min}$. It was confirmed that the etching rate increased as the applied $\mathrm{RF}$ power increased. This is because when high RP power is applied during atmospheric pressure plasma discharge, and the concentration of active ions increases due to the increase in plasma density thereby increasing the reactivity. Under RF power conditions of $100 \mathrm{~W}$ or more, the wafer surface was observed in the form of a pyramid of a needle-like structure. As the RF power increased, the chemical reaction became active and the movement of electrons and ions rapidly increased, and accordingly, the etching rate increased. It was 
found that the surface reflectance was decreased as the height of the pyramid structure increased and the slope increased after the RIE process. The lowest reflectance of $1.24 \%$ was confirmed under the RF power conditions of $100 \mathrm{~W}$. An inverted pyramid structure was formed at an RF power of $125 \mathrm{~W}$. Under RF power conditions of $150 \mathrm{~W}$ or more, it was confirmed that the surface of the wafer was over-etched, resulting in a non-uniform pyramidal shape, and thus the surface characteristics of the wafer were degraded and the reflectance increased again.
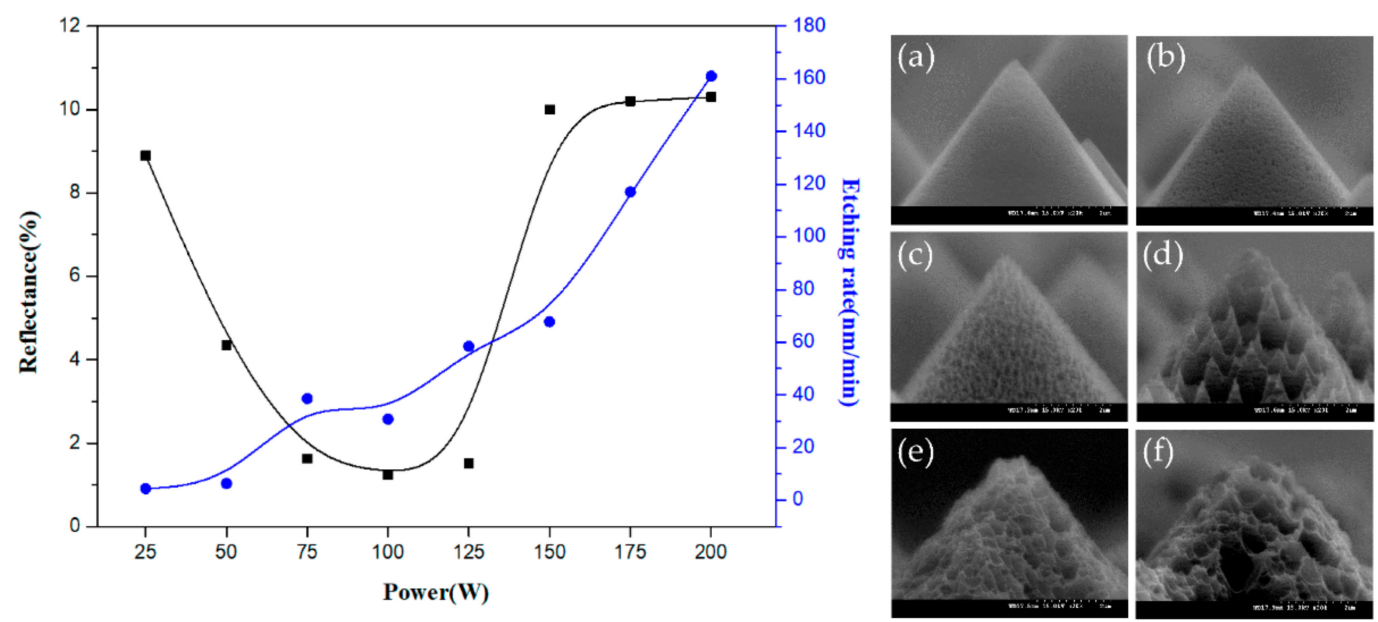

Figure 13. Reflectance and cross-section SEM images of wafer surfaces according to RF power for the two-step etching process with alkali solution and RIE: (a) $25 \mathrm{~W}$, (b) $50 \mathrm{~W}$, (c) $75 \mathrm{~W}$, (d) $125 \mathrm{~W}$, (e) $150 \mathrm{~W}$, and (f) $200 \mathrm{~W}$.

It was confirmed that the pyramid structure on the surface through the two-step surface etching process uniformly covers the entire area of the wafer. Figure 14 displays a graph showing reflectance characteristics according to the pyramid structure. The reflectance characteristics were measured in the wavelength range of $400-1000 \mathrm{~nm}$, and the reflectance of the textured wafer surface ranged from 9.11 to $1.2 \%$. In the case of the micro-sized pyramid, the surface reflectance of the wafer was approximately $9 \%$, and the nano-sized pyramid formed through RIE and MACE showed surface reflectances of $3.87 \%$ and $2.36 \%$, respectively. In the case of two-step etching through $\mathrm{KOH}$ and RIE, the reflectance was approximately $1.24 \%$, and in the case of two-step etching through $\mathrm{KOH}$ and MACE, the reflectance was approximately $1.3 \%$. The reflectance values of the $\mathrm{Si}$ wafers etched with two-step processes are lower than where one-step processes were used. This is expected to increase solar cell efficiency because optical loss can be reduced by improving reflectance characteristics. In order to analyze the effect of surface reflectance on cell characteristics, the quantum efficiency of the cell fabricated through the process of an emitter, a passivation film formation, and an electrode formation after the surface etching process were measured.

Quantum efficiency characteristics were compared to conduct electrical analysis based on the structural analysis of the emitter layer according to the pyramid structure. Figure 15 shows a graph of the quantum efficiency characteristics according to various etching process methods. Although the reflectance of the wafer after surface etching was the lowest in the alkali solution and MACE process, it was confirmed that the quantum efficiency value of the etching process with alkali solution alone was higher. In particular, it can be seen that the difference of the quantum efficiency value is large in the short wavelength band. 


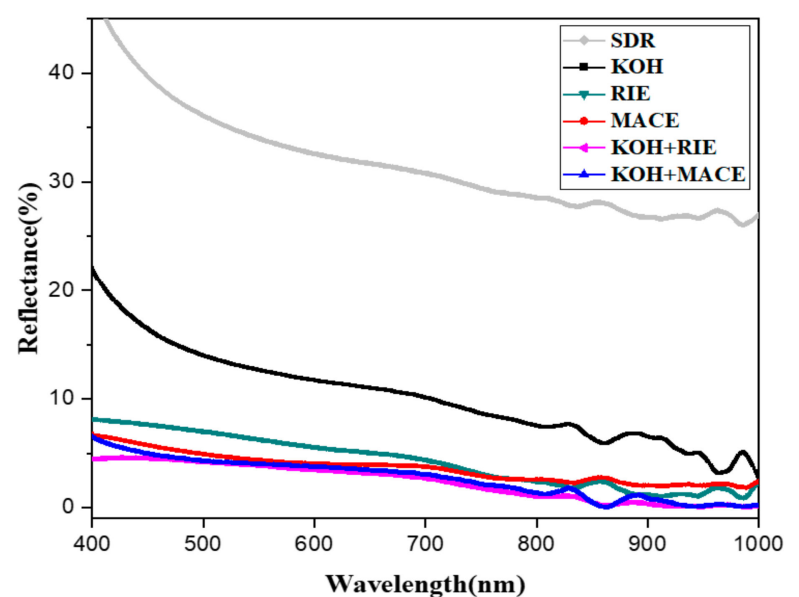

(a)

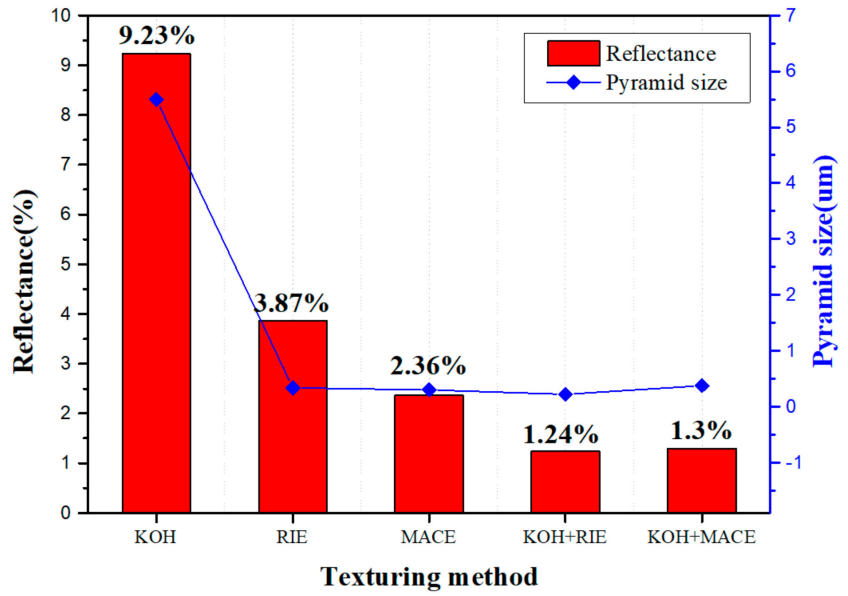

(b)

Figure 14. Reflectance characteristics and pyramid size according to various etching process methods: (a) reflectance with etching process methods in the wavelength range of 400 1000 $\mathrm{nm}$ and (b) a comparison of reflectance when different etching process methods were utilized.

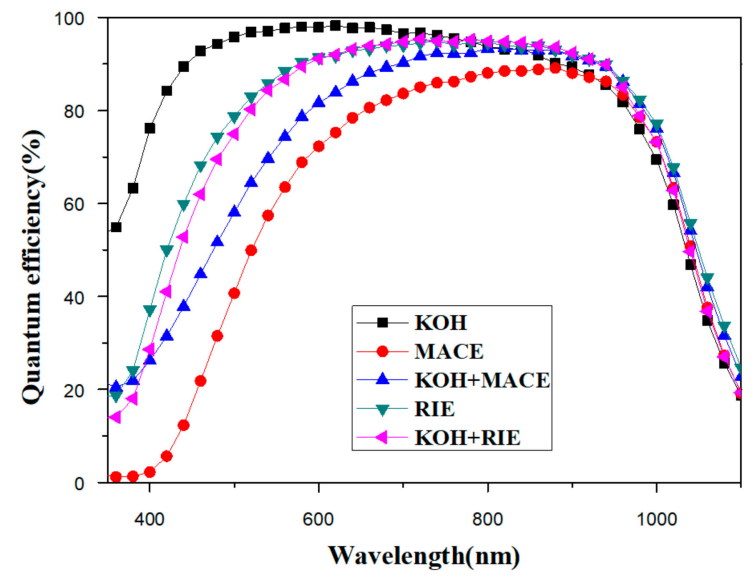

(a)

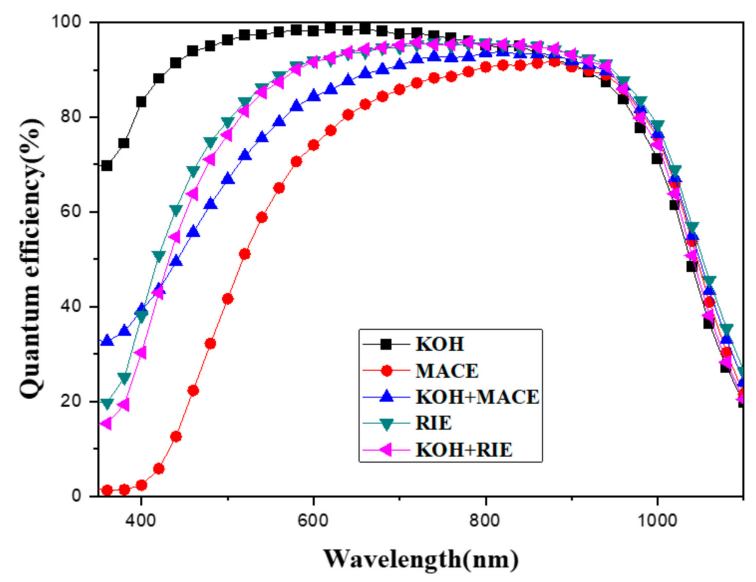

(b)

Figure 15. Quantum efficiency characteristics according to various etching process methods: (a) external and (b) internal.

In order to form an emitter layer that serves to separate electron-hole pairs generated by light energy by an internal electric field, a doping process was performed on a Si wafer, formed with various sized pyramids, using a doping furnace. The doping process was divided into two stages: pre-deposition and drive-in. The pre-deposition process is a process that supplies doping atoms to the semiconductor wafer surface. The drive-in process is a process of diffusing impurity atoms pre-deposited on the wafer surface into the wafer. In general, in the case of a c-Si solar cell, an n-type emitter layer is formed on a p-type wafer using a $\mathrm{POCl}_{3}$ solution. The $\mathrm{POCl}_{3}$ solution is maintained within $25^{\circ} \mathrm{C}$ and bubbles are generated by nitrogen gas. The generated bubbles contain $\mathrm{POCl}_{3}$ and are transported into the doping furnace by nitrogen gas. In the process transportation, they mix with oxygen $\left(\mathrm{O}_{2}\right)$ gas to produce $\mathrm{P}_{2} \mathrm{O}_{5}$, which is deposited on the wafer surface. The injection of $\mathrm{O}_{2}$ gas during the diffusion process causes the growth of an oxide film by a reaction between the $\mathrm{P}_{2} \mathrm{O}_{5}$ gas and the Si wafer, and this oxide film is generally known as phosphosilicateglass (PSG). This process is represented by the formula as follows. The PSG layer is an oxide film in which phosphorus is diffused relatively thickly in comparison to an oxide film grown during a normal oxidation process under the same temperature and time conditions. Accordingly, after the diffusion process, the PSG film was removed using a $10 \%$ diluted HF solution. It is very important to measure the distribution of 
the doping concentration and the doping profile of the doping depth after the emitter formation process. The doping profile is mainly measured using secondary ion mass spectroscopy (SIMS). This analysis method is difficult to accurately measure and can only be measured using expensive analysis equipment. As such, a selective etching analysis was performed using SEM instead of the SIMS analysis method in this study. This is a method of analysis that uses a relative comparison value by forming a step by the difference in etch rate between the emitter layer and the non-emitter layer. Figure 16 shows a schematic diagram of the selective etching (SE) analysis. The etching solution for SE consisted of HF: $\mathrm{HNO}_{3}: \mathrm{CH}_{3} \mathrm{COOH}=1: 100: 25$, and the doped wafer was etched for $5 \mathrm{~s}$. It is only possible to form an accurate step if there exists a passivation layer on the emitter layer, as this prevents additional etching on the top surface. In this paper, the effect of the pyramid structure on the emitter formation process was analyzed based on the results obtained through the previous experiment.

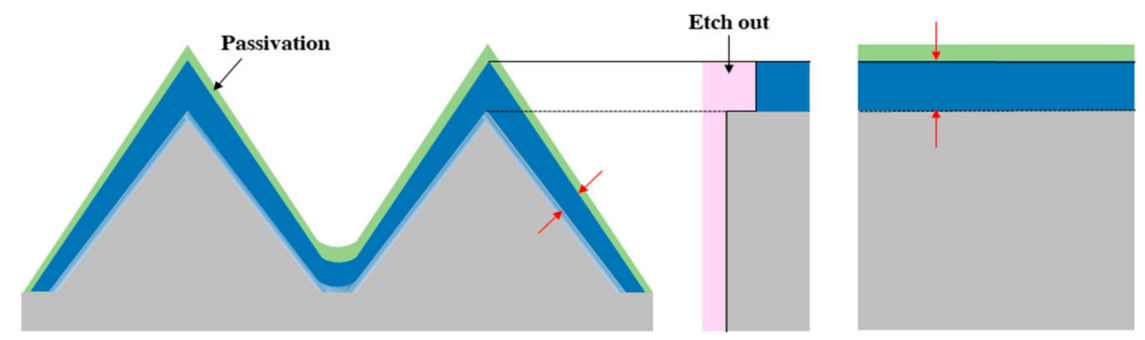

Figure 16. Schematic diagram of selective etching (SE) analysis.

After the surface etching process, the emitter layer was formed using a furnace. Figure 17 shows a cross-section SEM image of the wafer after the emitter formation process according to various etching process methods. The SEM image is the result of the formation of the n-type emitter and clearly shows the emitter formation structure according to the pyramid structure. Figure 17a is a result of observing the emitter layer formed on the micro-sized pyramid wafer, where it can be seen that a uniform doped layer is formed. In the nano-sized pyramid wafers of Figure $17 \mathrm{~b}-\mathrm{e}$, it can be observed that the emitter layer has a non-uniform formation compared to the micro-sized pyramid structure. This is judged by the influence of the dopant in the deposition step and the diffusion depth in the diffusion step during emitter formation, and can be explained through a schematic diagram of the formation process of the emitter layer, as shown in Figure 18. To form an emitter on the surface-textured wafer, $\mathrm{POCl}_{3}$ and $\mathrm{O}_{2}$ are injected into the furnace and deposited through pre-deposition and post-diffusion steps. The chemical reaction formula for $\mathrm{P}$ diffusion using a liquid source is as follows:

$$
\begin{gathered}
4 \mathrm{POCl}_{3}+3 \mathrm{O}_{2} \rightarrow 2 \mathrm{P}_{2} \mathrm{O}_{5}+6 \mathrm{Cl}_{2} \uparrow \\
2 \mathrm{P}_{2} \mathrm{O}_{5}+5 \mathrm{Si} \rightarrow 4 \mathrm{P}+5 \mathrm{SiO}_{2}
\end{gathered}
$$

$\mathrm{POCl}_{3}$ and $\mathrm{O}_{2}$ gas react in a chamber at a high temperature of approximately $800{ }^{\circ} \mathrm{C}$ to form a $\mathrm{P}_{2} \mathrm{O}_{5}$ layer on the wafer surface. This step is called the pre-deposition step. In this state, when high-temperature heat treatment is performed, the $\mathrm{P}$ atoms of $\mathrm{P}_{2} \mathrm{O}_{5}$ diffuse to the Si surface to form an emitter layer. This step is called the post-diffusion step. At this time, the dopant deposited on the wafer surface and the diffusion of the $\mathrm{P}$ is greatly influenced by the pyramidal structure of the wafer. In the case of a micro-sized pyramid structured wafer, as shown in Figure 18a, the thickness of the top and valley portions of the PSG layer is different. This is because the PSG layer is deposited thinly on the top portion of the pyramid structure due to the tensile properties present. In the valley portions of the pyramid structure, a thick PSG layer is deposited due to the compressive properties present. The thicker PSG layer forms a higher P surface concentration, and a deeper emitter layer is formed in the post-diffusion process. In the case of a micro-sized pyramid, it was observed that the side of the pyramid and the valley portion could form an emitter 
layer of similar thickness, and the top portion had more diffusion of the dopant and the emitter layer was thicker. In the case of a wafer having a nano-sized pyramid structure as shown in Figure 18b, more valley area is occupied in comparison to the same area of a micro-sized pyramid structure. Like the micro-sized pyramid, a thicker PSG layer is formed in the valley area with the nano-sized pyramid structure. The nano-sized pyramid structure may have a thicker PSG layer than the micro-sized pyramid structure due to the large number of valleys $[27,28]$. Accordingly, the emitter layer was formed deeper than the micro-sized pyramid structure in the nano-sized pyramid structure wafer. Based on the non-uniformity of the emitter layer observed through the SE analysis, it can be concluded that the formation of the emitter layer according to the pyramid structure has an effect on the number of tops and valleys compared to the same area.
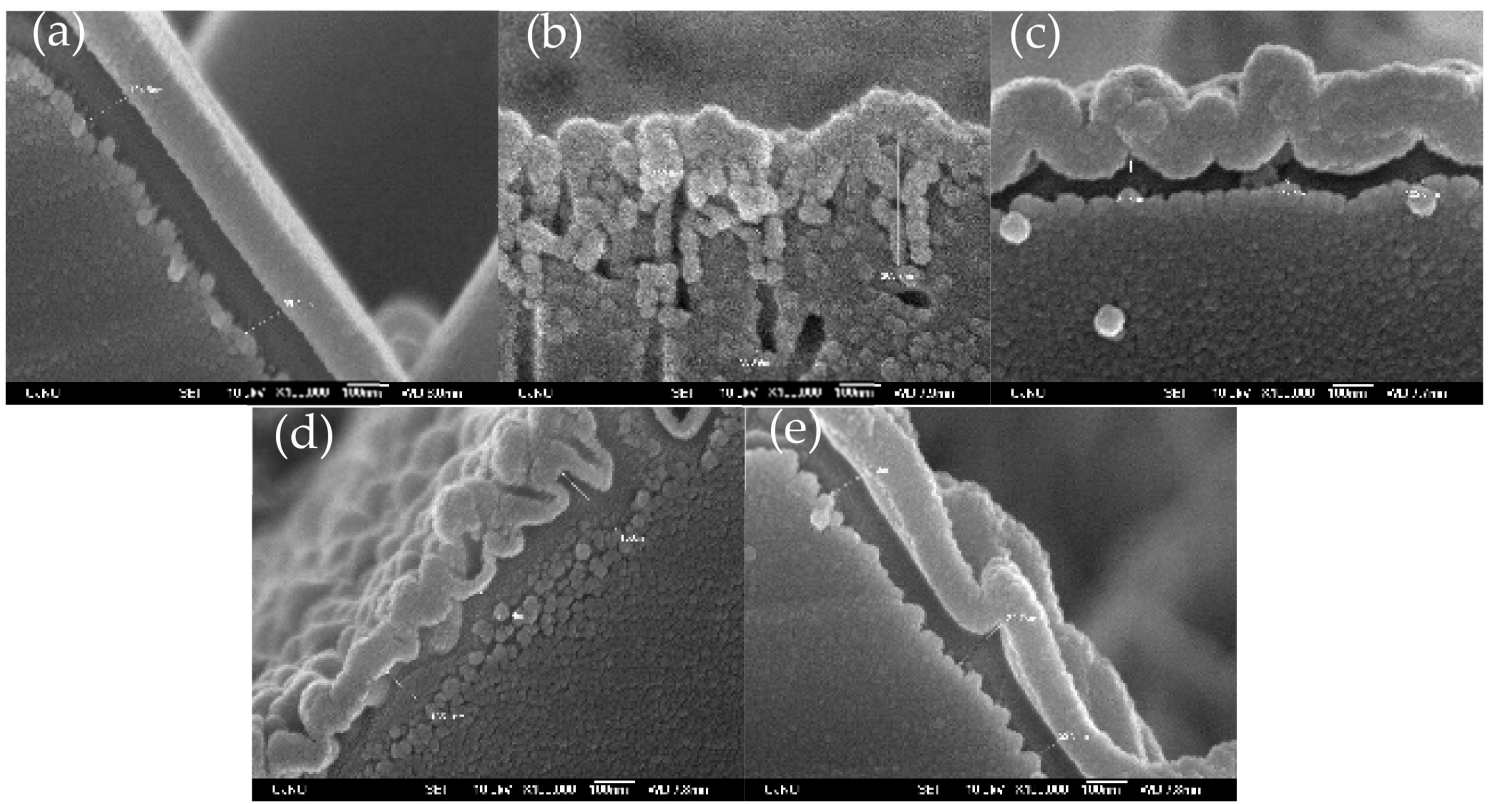

Figure 17. Cross-section SEM images of wafer after emitter formation process according to various etching process methods: (a) Alkali solution, (b) MACE, (c) RIE, (d) Alkali solution+MACE, (e) Alkali solution+RIE.

(a)

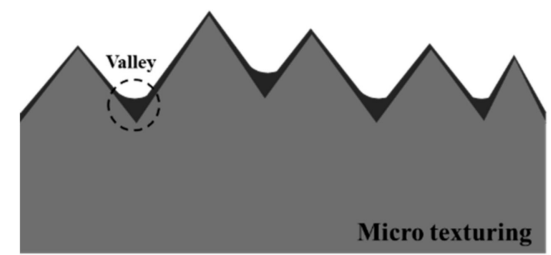

Pre-deposition by $\mathrm{POCl}_{3}$ Doping

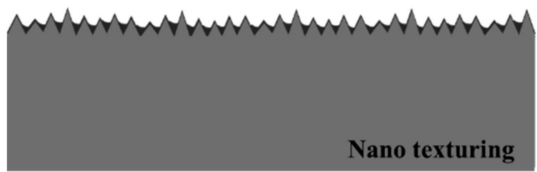

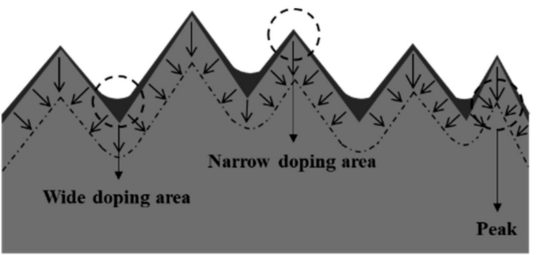

Drive-in

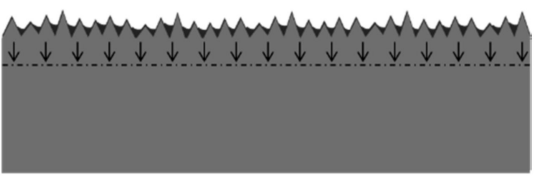

Figure 18. Schematic diagram of the emitter formation process according to pyramid size: (a) Microsized pyramid, (b) Nano-sized pyramid.

As a result, although the reflectance of the wafer after the etching process was the lowest in the $\mathrm{KOH}+\mathrm{MACE}$ process, the quantum efficiency value of the $\mathrm{KOH}$ process alone was measured to be higher. This is because the recombination rate is high due to the low sheet resistance by the deep emitter layer of the nano-pyramidal structure. It is also expected to be as a result of the influence of the non-uniform emitter layer in the nano-pyramidal structure. Subsequently, in order to increase the efficiency of the cell, it can 
be seen that the surface of the nano-pyramid using the one-step etching process is more advantageous when considering the formation of the emitter layer rather than the surface of the micro-pyramid using the two-step etching process.

\section{Conclusions}

In this paper, pyramid structures of various sizes were formed on wafers through various etching methods. First of all, one-step etching processes were performed by using the alkali solution method, MACE method, and RIE method. Next, two-step etching processes were performed by using the alkali solution + MACE methods and alkali solution + RIE methods. The micro-sized pyramid-structured wafer showed a reflectance of approximately $9.11 \%$, and the nano-sized pyramid-structured wafer showed a low reflectance in the range of approximately 1 to $5 \%$. Accordingly, it was determined that the characteristics of the cell fabricated from the nano-sized pyramid-structured wafer having low reflectance would be higher, but it was confirmed that the quantum efficiency characteristics were higher in the micro-pyramidal-structured wafer. It is believed that this is the influence of the non-uniform formation of the emitter layer. In addition, this is because the sheet resistance is low and the recombination rate is high due to the deep emitter layer having a nano-pyramidal structure. As a result, it was confirmed that the micro-sized pyramidstructured wafer exhibited higher quantum efficiency characteristics due to the influence of the doping layer. A surface texture process with low reflectance is very important for improving efficiency. However, if a process with a uniform doping profile is developed according to the pyramid surface structure, short-wavelength region responsiveness can be improved, which can increase short-circuit current density. In addition, if the cell is fabricated by forming an electrode in consideration of the particle size of the Ag paste according to the pyramid structure, the contact area between the Ag paste particles and the doped wafer surface increases, the fill factor is increased. Thus, it is expected that a high-efficiency cell can be obtained.

Author Contributions: J.E.P. and C.-S.H. are the main authors; writing-original draft preparation and writing-review and editing, J.E.P. and C.-S.H.; investigation, W.S.C.; supervision, D.L. All authors participated in the discussion of the results, reviewed the manuscript, and provided input for editing. All authors have read and agreed to the published version of the manuscript.

Funding: This work was supported by the Korea Electric Power Corporation. (Grant number: R17XA05-1), and the Korea Institute of Energy Technology Evaluation and Planning(KETEP) and the Ministry of Trade, Industry \& Energy(MOTIE) of the Republic of Korea (No. 20193020010650).

Institutional Review Board Statement: Not applicable.

Informed Consent Statement: Not applicable.

Data Availability Statement: Not applicable.

Conflicts of Interest: The authors declare no conflict of interest.

\section{References}

1. Snapshot of Global PV Markets 2020; Gaëtan Masson, IEA PVPS Task 1 Operating Agent; Snapshot of Global PV Markets; IEA: Paris, France, 2020; p. 19. ISBN 978-3-906042-94-7.

2. Lee, S.H. Development of High-Efficiency Silicon Solar Cells for Commercialization. J. Korean Phys. Soc. 2001, $39,369-373$.

3. Paviet-Salomon, B.; Gall, S.; Monna, R.; Manuel, S.; Slaoui, A. Analysis of laser-doped phosphorus emitters. Energy Procedia 2011, 8, 214-219. [CrossRef]

4. Hübner, A.; Aberle, A.G.; Hezel, R. Novel cost-effective bifacial silicon solar cells with $19.4 \%$ front and $18.1 \%$ rear efficiency. Appl. Phys. Lett. 1997, 70, 1008-1010. [CrossRef]

5. Jiang, F.; Liu, T.; Luo, B.; Tong, J.; Qin, F.; Xiong, S.; Li, Z.; Zhou, Y. A two-terminal perovskite/perovskite tandem solar cell. J. Mater. Chem. A 2016, 4, 1208-1213. [CrossRef]

6. Zhao, D.; Yu, Y.; Wang, C.; Liao, W.; Shrestha, N.; Grice, C.R.; Cimaroli, A.J.; Guan, L.; Ellingson, R.J.; Zhu, K.; et al. Low-bandgap mixed tin-lead iodide perovskite absorbers with long carrier lifetimes for all-perovskite tandem solar cells. Nat. Energy 2017, 2, 17018. [CrossRef] 
7. Martin, A. Green, Silicon Solar Cells: Advanced Principles \& Practice; Centre for Photovoltaic Devices and Systems: Sydney, Australia, 1995; p. 366.

8. Abdullah, M.F.; Lghoul, M.A.; Naser, H.; Asim, N.; Ahmadi, S.; Yatim, B.; Sopian, K. Research and development efforts on texturization to reduce the optical losses at front surface of silicon solar cell. Renew. Sustain. Energy Rev. 2016, 66, 380-398. [CrossRef]

9. Park, H.; Kwon, S.; Lee, J.S.; Lim, H.J.; Yoon, S.; Kim, D. Improvement on surface texturing of single crystalline silicon for solar cells by saw-damage etching using an acidic solution. Sol. Energy Mater. Sol. Cells 2009, 93, 1773-1778. [CrossRef]

10. Gu, Y.; Xue, C.; Zheng, M. Technologies to reduce optical losses of silicon solar cells. Adv. Mater. Res. 2014, 953-954, 91-94. [CrossRef]

11. Lee, D.B. Anisotropic Etching of Silicon. J. Appl. Phys. 1969, 40, 4569-4574. [CrossRef]

12. Wang, S.; Xu, Z.; Gou, X.; Huang, X.; Zhou, S. Study of Nano Texturing on Multi-crystalline Silicon Solar Cells. IOP Conf. Ser. Earth Environ. Sci. 2020, 453, 1-6. [CrossRef]

13. Oxtoby, D.W. Chemistry: Science of Change, 3rd ed.; Saunders College: Rochester, NY, USA, 1997; p. 1152.

14. Yoo, J. Reactive ion etching (RIE) technique for application in crystalline silicon solar cells. Sol. Energy 2010, 84, 730-734. [CrossRef]

15. Halima, A.F.; Zhang, X.; MacFarlane, D.R. Metal-Free Black Silicon for Solar-powered Hydrogen Generation. Electrochim. Acta 2017, 235, 453-462. [CrossRef]

16. Chartier, C.; Bastide, S.; Lévy-Clément, C. Metal-assisted chemical etching of silicon in $\mathrm{HF}-\mathrm{H}_{2} \mathrm{O}_{2}$. Electrochim. Acta 2008, 53, 5509-5516. [CrossRef]

17. Unagami, T. Formation Mechanism of Porous Silicon Layer by Anodization in HF Solution. J. Electrochem. Soc. 1980, 127, 476. [CrossRef]

18. Moreno, M.; Murias, D.; Martínez, J.; Reyes-Betanzo, C.; Torres, A.; Ambrosio, R.; Rosales, P.; Roca ICabarrocas, P.; Escobar, M. A comparative study of wet and dry texturing processes of c-Si wafers for the fabrication of solar cells. Sol. Energy 2014, 101, 182-191. [CrossRef]

19. Rosli, S.A.; Aziz, A.A.; Hamid, H.A. Characteristics of RIE SF6/O $/$ /Ar Plasmas on n-Silicon Etching. In Proceedings of the 2006 IEEE International Conference on Semiconductor Electronics, Kuala Lumpur, Malaysia, 29 October-1 December 2006; pp. 851-855.

20. Abdullah, M.F.; Hashim, A.M. Reflectance Characteristics of Silicon Surface Fabricated with the Arrays of Uniform Inverted Pyramid Microstructures in UV-Visible Range. Sains Malays. 2019, 48, 1163-1169. [CrossRef]

21. Li, H.; Kim, K.; Hallam, B.; Hoex, B.; Wenham, S.; Abbott, M. POCl3 diffusion for industrial Si solar cell emitter formation. Front. Energy 2016, 11, 42-51. [CrossRef]

22. Werner, S.; Mourad, S.; Hasan, W.; Wolf, A. Structure and composition of phosphosilicate glass systems formed by POCl3 diffusion. Energy Procedia 2017, 124, 455-463. [CrossRef]

23. Vazsonyi, E.; De Clercq, K.; Einhaus, R.; Van Kerschaver, E.; Said, K.; Poortmans, J.; Szlufcik, J.; Nijs, J. Improved anisotropic etching process for industrial texturing of silicon solar cells. Sol. Energy Mater. Sol. Cells 1999, 57, 179-188. [CrossRef]

24. Abdur-Rahman, E.; Alghoraibi, I.; Alkurdi, H. Effect of Isopropyl Alcohol Concentration and Etching Time on Wet Chemical Anisotropic Etching of Low-Resistivity Crystalline Silicon Wafer. Int. J. Anal. Chem. 2017. [CrossRef]

25. Hsu, C.-H.; Liu, S.-M.; Lien, S.-Y.; Zhang, X.-Y.; Cho, Y.-S.; Huang, Y.-H.; Zhang, S.; Chen, S.-Y.; Zhu, W.-Z. Low Reflection and Low Surface Recombination Rate Nano-Needle Texture Formed by Two-Step Etching for Solar Cells. Nanomaterials 2019, 9, 1392. [CrossRef] [PubMed]

26. Huang, Z.G.; Lin, X.X.; Zeng, Y.; Zhong, S.H.; Song, X.M.; Liu, C.; Yuan, X.; Shen, W.Z. One-step-MACE nano/microstructures for high-efficient large-size multicrystalline Si solar cells. Sol. Energy Mater. Sol. Cells 2015, 143, 302-310. [CrossRef]

27. Voyer, C.; Buettner, T.; Bock, R.; Biro, D.; Preu, R. Microscopic homogeneity of emitters formed on textured silicon using in-line diffusion and phosphoric acid as the dopant source. Sol. Energy Mater. Sol. Cells 2009, 93, 932-935. [CrossRef]

28. Dastgheib-Shirazi, A.; Steyer, M.; Micard, G.; Wagner, H.; Altermatt, P.P.; Hahn, G. Relationships between Diffusion Parameters and Phosphorus Precipitation during the $\mathrm{POCl}_{3}$ Diffusion Process. Energy Procedia 2013, 38, 254-262. [CrossRef] 